\title{
The thermodynamic structure of summer Arctic stratocumulus and the dynamic coupling to the surface
}

\author{
G. Sotiropoulou ${ }^{1,2}$, J. Sedlar ${ }^{1,2}$, M. Tjernström ${ }^{1,2}$, M. D. Shupe ${ }^{3,4}$, I. M. Brooks ${ }^{5}$, and P. O. G. Persson ${ }^{3,4}$ \\ ${ }^{1}$ Department of Meteorology, Stockholm University, Stockholm, Sweden \\ ${ }^{2}$ Bert Bolin Center for Climate Research, Stockholm University, Stockholm, Sweden \\ ${ }^{3}$ Cooperative Institute for Research in the Environmental Sciences, University of Colorado, Boulder, Colorado, USA \\ ${ }^{4}$ NOAA Earth System Research Laboratory, Boulder, Colorado, USA \\ ${ }^{5}$ Institute for Climate \& Atmospheric Science, School of Earth \& Environment, University of Leeds, Leeds, UK \\ Correspondence to: G. Sotiropoulou (georgia@misu.su.se)
}

Received: 16 December 2013 - Published in Atmos. Chem. Phys. Discuss.: 11 February 2014

Revised: 24 October 2014 - Accepted: 27 October 2014 - Published: 28 November 2014

\begin{abstract}
The vertical structure of Arctic low-level clouds and Arctic boundary layer is studied, using observations from ASCOS (Arctic Summer Cloud Ocean Study), in the central Arctic, in late summer 2008. Two general types of cloud structures are examined: the "neutrally stratified" and "stably stratified" clouds. Neutrally stratified are mixedphase clouds where radiative-cooling near cloud top produces turbulence that generates a cloud-driven mixed layer. When this layer mixes with the surface-generated turbulence, the cloud layer is coupled to the surface, whereas when such an interaction does not occur, it remains decoupled; the latter state is most frequently observed. The decoupled clouds are usually higher compared to the coupled; differences in thickness or cloud water properties between the two cases are however not found. The surface fluxes are also very similar for both states. The decoupled clouds exhibit a bimodal thermodynamic structure, depending on the depth of the sub-cloud mixed layer (SCML): clouds with shallower SCMLs are disconnected from the surface by weak inversions, whereas those that lay over a deeper SCML are associated with stronger inversions at the decoupling height. Neutrally stratified clouds generally precipitate; the evaporation/sublimation of precipitation often enhances the decoupling state. Finally, stably stratified clouds are usually lower, geometrically and optically thinner, non-precipitating liquidwater clouds, not containing enough liquid to drive efficient mixing through cloud-top cooling.
\end{abstract}

\section{Introduction}

Rapid changes in the Arctic climate during the past decades (Serreze et al., 2000; Overland et al., 2004; ACIA, 2005) have led to widespread attention in the global climate research community. Annual average near-surface temperatures in the Arctic have increased by over a factor of 2 compared to the rest of the world (ACIA, 2005; Richter-Menge, 2010) and the sea-ice extent has been declining at an accelerating rate, especially during summer and early fall (Comiso, 2002; Nghiem et al., 2007; Stroeve et al., 2012). Extreme anomalies in the mid-September ice extent minima over the last decade (Serreze et al., 2007; Stroeve et al., 2012), including record minima in 2007 (Maslanik et al., 2007; Lindsay et al., 2009) and 2012 (Simmonds and Rudeva, 2012; Devasthale et al., 2013; Zhang et al., 2013) are indicative of an increasing "Arctic amplification" (Serreze and Francis, 2006; Serreze and Berry, 2011) signaling rapid climate change. This amplification has been attributed to several factors that affect the surface energy budget; one is the surfacealbedo feedback (Perovich et al., 2008; Stroeve et al., 2012) and how changes at the surface impact the cloud response (Kay and Gettelman, 2009), and vice versa. Other amplification hypotheses exist, such as the lapse-rate feedback associated with the vertical structure of warming (Bintanja et al., 2012; Pithan and Mauritsen, 2014), or how changes in the large-scale Northern Hemisphere atmospheric circulation (Graversen et al., 2008; Kapsch et al., 2013) may result in changes in the clouds and hence the surface energy balance. 
Global climate models exhibit a large variation in global and regional sensitivity to imposed large-scale forcing, which has been attributed to differences in cloud parameterization schemes and cloud feedbacks, especially those of low-level clouds (Bony and Dufresne, 2005; Webb et al., 2006; Lauer et al., 2010). To understand the Arctic climate system, a detailed understanding of cloud processes and their impact on both the surface and atmospheric thermodynamic structure are required (Curry et al., 1996). In general, solar radiation is reflected by clouds, leading to a radiative cooling at the surface, whereas longwave radiation is both absorbed and emitted by clouds. Over the Arctic, where surface albedo and solar zenith angles are relatively large and clouds are predominantly low, the net effect on the sea ice surface is a warming (Shupe and Intrieri, 2004; Sedlar et al., 2011), except possibly for a short period in summer, when the surface albedo is reduced by sea ice melt (Intrieri et al., 2002). The influence of the clouds on the surface energy budget depends on several parameters, such as the cover, phase, and vertical and horizontal cloud distribution, etc. (Randall et al., 1998); combining all the factors is complex and it is no surprise that clouds are very difficult to model.

Low-level clouds are very frequent in the Arctic, especially during the summer when they occur for 80-90\% of the time (Curry and Ebert, 1992; Wang and Key, 2005; Tjernström, 2005; Shupe et al., 2011). Clouds below $3 \mathrm{~km}$ a.s.1. (above surface level; unless otherwise stated all heights will be given above the surface) over the Arctic are most frequently mixed-phase, consisting of both droplets and ice crystals (Shupe, 2011); the liquid is often concentrated in a relatively thin layer near the top of the cloud, with nearcontinuous precipitation consisting of frozen drizzle or ice crystals formed within the liquid layer (Shupe et al., 2008). These clouds have been observed to persist for long durations - hours to days (Shupe et al., 2011) - and are believed to have a critical impact on the surface energy balance (Intrieri et al., 2002; Persson et al., 2002; Shupe and Intrieri, 2004; Sedlar et al., 2011). Both shortwave and longwave radiation are very sensitive to cloud phase; longwave opacity (emissivity) increases asymptotically to unity with the cloud liquid water path, while shortwave reflection to space increases with increasing numbers of smaller, spherical cloud droplets (e.g., Twomey, 1977; Stephens, 1978). The end result is more longwave radiation emitted to the surface and less shortwave radiation transmitted to the surface when liquid droplets are present than for ice-only clouds (Shupe and Intrieri, 2004; Prenni et al., 2007).

Mixed-phase clouds are particularly poorly handled by current climate models (Tjernström et al., 2005, 2008; Karlsson and Svensson, 2010), suggesting that the processes that support the maintenance of these clouds in the Arctic are not fully understood. These processes are discussed in Morrison et al. (2012). For example, turbulence generated by cloud-top cooling and in-cloud upward air motion play a critical role; the layer with largest liquid concentrations near cloud top emits longwave radiation to space (Pinto, 1998), which decreases static stability in the clouds and leads to a buoyant overturning circulation (e.g., Nicholls, 1984). These cloud-driven turbulent motions promote the growth of both liquid and ice, rather than just ice growing at the expense of the liquid (Korolev, 2007) as would intuitively be expected in an ice/liquid mixture. Moreover, mixing from below cloud base may also be ongoing, driven by surface forcing and/or advection in the lower troposphere, leading to an upward transfer of heat and moisture. The coupling, or lack thereof (hence referred to as decoupling), between cloud- and surface-generated turbulence may be critically important for the sustenance of mixed-phase clouds.

Because of the strongly stable near-surface conditions that often occur during Arctic winter to early spring (Kahl, 1992; Curry, 1986), surface fluxes are often considered to have no significant contribution to the cloud's moisture during these seasons; this changes from late spring until October when both open ice-free ocean and melting sea ice expose a vast source of heat and moisture to the relatively cool and dry lower atmosphere (Pinto and Curry, 1995). Analysis of the vertical atmospheric structure in late summer from four different expeditions, including the Arctic Summer Cloud Ocean Study (ASCOS; www.ascos.se, also see Tjernström et al., 2014), revealed a neutrally stratified layer extending from the surface up to about 300-600 m (Tjernström et al., 2012), which indicates that the surface and the boundarylayer clouds could potentially be thermodynamically coupled.

Shupe et al. (2013) investigated the interactions between the cloud and boundary layer using 1 week of observations from ASCOS and found, however, that for this time period, such coupling took place only $25 \%$ of the time; the rest of the time the cloud layer was decoupled from the surface. In addition, even when clouds were coupled with the surface, surface fluxes did not seem to drive this coupling; instead they simply responded to the mixed-layer processes aloft, driven primarily by in-cloud generated turbulence.

The present study is also based on ASCOS data and provides a complementary view on cloud-surface interactions to that by Shupe et al. (2013); they analyzed three case studies, each 9 to $12 \mathrm{~h}$ long, to provide a process-level view of what happens in these clouds; the time evolution and the transitions between coupled and decoupled states were important aspects of this study. They also provided a statistical description of some characteristics of the coupling states, although for a limited time period and based only on single-cloud layer profiles. The present study offers a complete statistical analysis on cloud-surface coupling and the main purpose here is to identify properties in the thermodynamic structure that generally characterize the state of cloud-surface coupling and assess which factors drive these interactions. The connection between (de)coupling and precipitation structure is also investigated. Moreover, while in Shupe et al. (2013) only clouds that generate turbulence are examined, here we also 
identify clouds where the in-cloud mixing is inhibited; an attempt to explain why the generation of cloud-driven motions is prevented in these cases is also provided.

Apart from considering a different approach of the surface-cloud coupling issue, the two studies also differ in method. Shupe et al. (2013) used profiles of turbulence dissipation rate, derived from Doppler radar velocities, to determine the coupling state and the depth of the cloud-driven mixed layer below cloud base. Here we instead use vertical profiles of equivalent potential temperature, $\Theta_{\mathrm{E}}=\Theta(1+$ $\left.L Q_{\mathrm{v}} / C_{\mathrm{P}} T\right)$, a conserved quantity during moist adiabatic processes, to identify stability and stability changes within the cloud and sub-cloud layers. While deriving profiles of turbulence dissipation rate from the cloud radar requires more ideal conditions (e.g., active mixing) than observing the thermal structure of the lowest troposphere, our method allows us to examine profiles from all periods (Tjernström et al., 2012, 2013) of ASCOS, from the whole ice drift as well as the transit periods (to/from the ice drift). This allowed us to include substantially more data in our analysis with a larger variety of meteorological conditions, compared to only the week-long period characterized by relatively steady conditions and free-atmosphere subsidence. Moreover, the dissipation rate method does not allow examination of decoupling below $150 \mathrm{~m}$ (near the first radar vertical range gate), whereas profiles of $\Theta_{\mathrm{E}}$ can indicate decoupling much closer to the surface.

The present study is organized as follows; Sect. 2 includes a brief description of ASCOS, the atmospheric conditions and the instrumentation deployed; included here is also a discussion on the analysis methods. Section 3 describes the results of this study, first examining the characteristics of surface turbulence and cloud properties and then examining how the boundary layer responds to these interactions - or the lack thereof. A discussion and the conclusions are given in Sects. 4 and 5, respectively.

\section{Data and methods}

\subsection{ASCOS}

ASCOS operated under the fourth International Polar Year (IPY 2007-2009) and was an intensive field experiment observing many aspects of the atmosphere, sea ice and the upper ocean for 40 days through August and late September 2008, in the North Atlantic sector of the central Arctic Ocean $\left(\sim 87.2^{\circ} \mathrm{N}\right)$. Tjernström et al. (2014) provides a detailed description of this endeavor, as well as of the instruments and measurement strategies that were deployed. ASCOS was conducted on the Swedish ice-breaker Oden, which left Longyearbyen on Svalbard on 2 August (day of year; DoY 215) and returned on 9 September (DoY 253). Between 12 August (DoY 225) and 2 September (DoY 246), Oden was moored to and drifted with a $3 \times 6 \mathrm{~km}$ ice-floe, where an ice camp was established. The drift track was approximately from $87^{\circ} 21^{\prime} \mathrm{N}$ and $01^{\circ} 29^{\prime} \mathrm{W}$ to $87^{\circ} 09^{\prime} \mathrm{N}$ and $11^{\circ} 01^{\prime} \mathrm{W}$; this period will be referred to as the "ice drift". Note that the term "ice drift" is used here for the period when the icebreaker was moored to and drifted with the ice; however, the whole data set used in this study, including the transitions, comes from within the ice pack. Ice cover conditions were fairly similar throughout ASCOS, although the surface melt ended and the freeze up started towards the end (Sedlar et al., 2011; Sirevaag et al., 2011).

Detailed observations of Arctic clouds are sparse, limited in time and space to a small number of intensive observational campaigns, including SHEBA (Uttal et al., 2002) and AOE-2001 (Leck at al., 2004; Tjernström et al., 2004a) or the pan-Arctic observatories discussed in Shupe et al. (2011). One aim of ASCOS was to study the formation and life cycle of low-level clouds, with a focus to better understand their impact on the surface energy budget, especially during the fall transition towards sea-ice freeze up. ASCOS included arguably the most comprehensive suite of instruments for observing surface, atmospheric and cloud processes over a remote sea-ice environment (Tjernström et al., 2014).

Large-scale atmospheric conditions during ASCOS are documented in Tjernström et al. (2012) while detailed descriptions of the meteorological conditions encountered during ASCOS ice drift are provided by Sedlar et al. (2011) and Tjernström et al. $(2012,2013)$; hence only a brief recap will be provided here. Sedlar et al. (2011) analyzed the surface energy budget during the ice drift and defined four periods with different energy budgets and cloud characteristics. Tjernström et al. (2012) included surface temperature variability and vertical structure of the lower troposphere and subsequently divided the first period into two sub-periods, defining five periods in total. These are the periods adopted here and Fig. 1 illustrates these five ice drift periods overlaid on the reflectivity from the vertically pointing cloud radar. DoYs prior to 226 and after 246 are during the transit towards and away from the ice drift, respectively.

The first (DoY 226-230) and second (DoY 230-234) periods during the ice drift had the largest positive surface energy residuals, indicating melt was still ongoing (Sedlar et al., 2011). Surface temperatures were primarily close to the melting point of fresh water during these periods. Both periods were affected by synoptic weather systems and deep frontal cloud structures, but the first was synoptically more active and significantly more variable in temperature than the second (Fig. 1). This period of synoptic activity ended on the evening of DoY 233. During the third period (DoY 234-236) a sharp drop in temperature was observed, down to $-6^{\circ} \mathrm{C}$. Quiescent conditions prevailed during these 2 days and an intermittent, and occasionally tenuous, low-level stratiform cloud or fog layer emerged below an upper level, optically thin cirrus layer (Sedlar et al., 2011).

On DoY 236, a frontal system produced heavy snow fall during much of the evening. After that, the following 4th 

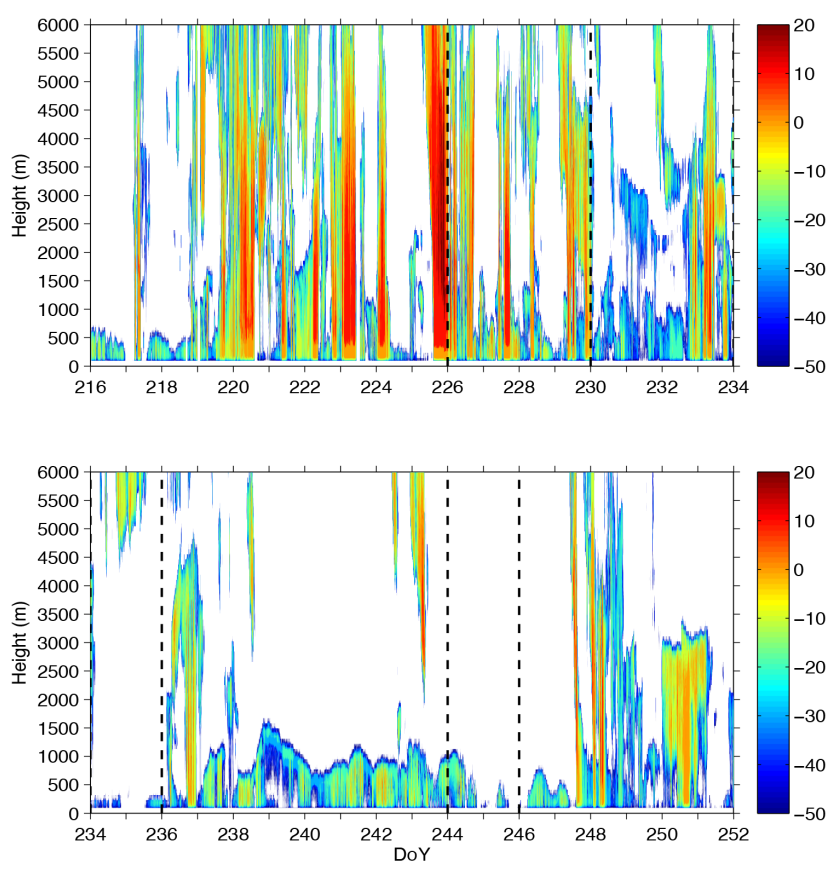

Figure 1. Radar reflectivity contour (colors, dBZ (radar reflectivity)) time-series for the ASCOS experiment, given in day of year (DoY) 2008. The vertical dashed lines differentiate the five periods of the ice drift (see Sect. 2.3 for a discussion on period characteristics). Periods prior to DoY 226 and after DoY 246 are the transit periods (before/after the ice drift). Reflectivity profiles are shown up to $6 \mathrm{~km}$.

period (DoY 236-244) was characterized by high pressure and large-scale subsidence in the free troposphere, with only weak frontal passages. Single and multi-layered stratiform clouds below $2 \mathrm{~km}$ were persistent for nearly the entire week (Sedlar et al., 2011), topped by thin liquid cloud layers with ice crystals growing within, and falling from, these layers. The surface temperature was somewhat higher, close to the freezing point of ocean water, but still below fresh-water melting. Sedlar et al. (2011) concluded that this period was vital to the transition of the surface towards the seasonal freeze up. These relatively steady conditions continued during the 5th period (DoY 244-246), when an area with partly clear skies and optically thin clouds was advected over the ASCOS site, allowing surface temperatures to plummet below $-12{ }^{\circ} \mathrm{C}$ and the autumn freeze up to initiate (Sedlar et al., 2011). Finally, during both transit periods, before and after the ice drift, numerous synoptic weather systems were encountered; see Tjernström et al. (2012) for detailed profiles of radar reflectivity and subjective analysis of frontal profiles during each of these periods.

\subsection{Instrumentation}

A detailed description of all ASCOS instrumentation is provided by Tjernström et al. (2014). Here, only basic informa- tion about the instruments used in this study is given, while further details can be found in the cited references.

Information on the vertical atmospheric structure is derived from radiosondes and a $60 \mathrm{GHz}$ scanning radiometer. Radiosoundings were released approximately every $6 \mathrm{~h}$. Although the limited temporal resolution is a major disadvantage, radiosondes provide accurate temperature, moisture and wind measurements. The scanning radiometer (Westwater et al., 1999) provides temperature profiles up to $1200 \mathrm{~m}$ with a vertical resolution of around $7 \mathrm{~m}$ near the surface, gradually deteriorating with altitude to about $200 \mathrm{~m}$ at $1 \mathrm{~km}$. A 5 min averaging window was applied to the $1 \mathrm{~Hz}$ raw data to improve the signal-to-noise ratio. The scanning radiometer has been shown to provide accurate measurements, with a low root mean square error relative to independent radiosondes up to $800 \mathrm{~m}$ (P. O. G. Persson, personal communication, 2013); above this height, the scanning radiometer temperatures gradually revert to the linear interpolation between the radiosonde profiles used as the a priori assumption in the retrieval process. Nevertheless, due to its high temporal resolution, and the fact that many of the cloud and sub-cloud layers are below $800 \mathrm{~m}$, these profiles provide a valuable coherent data set of temperature profiles.

Cloud boundaries and characteristics are, to a large extent, derived from a vertically pointing $35 \mathrm{GHz}$ Doppler Millimeter Cloud Radar (MMCR; Moran et al., 1998). The vertical resolution is $45 \mathrm{~m}$ with a lowest radar gate at $105 \mathrm{~m}$ and a time resolution of $10 \mathrm{~s}$. The measured Doppler spectrum was processed to estimate the three Doppler radar moments: radar reflectivity (dBZ), mean Doppler velocity $\left(\mathrm{m} \mathrm{s}^{-1}\right)$ and Doppler spectrum width $\left(\mathrm{m} \mathrm{s}^{-1}\right)$ in clouds and precipitation. The reflectivity, which is nominally proportional to hydrometeor size to the sixth power, is usually dominated by ice crystals since they are normally larger than liquid droplets. The fall velocity of the hydrometeors can also be used to assist in distinguishing hydrometeor phase; cloud droplets have a very small, nearly negligible, fall velocity, whereas ice crystals and drizzle/rain droplets generally fall with larger velocities. As is common in radar meteorology, a positive Doppler velocity is defined downward. The Doppler spectrum width can provide indications of multiple cloud phases, i.e., particles in the same volume with different fall speeds, and/or turbulence within the radar pulse volume.

Under most observed conditions, the MMCR can accurately identify cloud top; however when precipitation occurs between multi-layer clouds, the MMCR may not provide information on cloud top height for lower layers. The full Doppler spectra were used to create spectrographs of vertically resolved reflected power as a function of Doppler velocity. These proved useful for distinguishing multiple cloud layers when other sensors indicated the potential for cloud layering masked by precipitation; spectrographs are discussed in Sect. 2.3.

MMCR derived cloud boundaries are also complemented with additional remote sensors. Cloud base is derived using 
two laser ceilometers with a sampling interval of $15 \mathrm{~s}$. In general, laser ceilometers become attenuated by large concentrations of liquid droplets; this instrument is therefore able to penetrate precipitating layers of ice crystals and drizzle droplets and identify the vertical locations of up to three cloud bases, provided the lower cloud layers are not too optically thick. Once the return signal is attenuated, it is not possible to detect additional cloud layers aloft. A comparison of the two time series revealed relatively good agreement between the two ceilometers.

A dual-channel microwave radiometer provides vertically integrated liquid water path (LWP) retrievals with an uncertainty of $25 \mathrm{~g} \mathrm{~m}^{-2}$ (Westwater et al., 2001); ice water path (IWP) is estimated using a multi-sensor cloud phase classification and MMCR reflectivity power-law relationship (Shupe et al., 2005). Cloud condensation nuclei (CCN) concentration was measured by an in situ CCN counter (Roberts and Nenes, 2005), set at a constant supersaturation of $0.2 \%$, based on typical values used in other similar expeditions (Bigg and Leck, 2001; Leck et al., 2002). These CCN measurements were made on the ship via an inlet at $25 \mathrm{~m}$ above the surface.

Finally, turbulent fluxes are derived using two techniques. Eddy covariance measurements are available from the ice drift (12 August-1 September) at heights between the surface and $30 \mathrm{~m}$ from sensors deployed on masts on the ice. The uncertainty of individual turbulent flux estimates is not easy to determine but is generally considered to be around $10 \%$ (Andreas et al., 2005). Diffusional and rime icing on the turbulent flux instrumentation poses a more critical problem, and leads to time periods when turbulent fluxes could not be estimated. To maximize the use of this data, a single consensus time series was created from all available data, regardless of height, assuming it was all sampled within the so-called "constant-flux layer"; tests indicate that this is a reasonable approximation.

So-called "bulk turbulent fluxes", based on mean vertical differences, are less accurate than direct measurements but data from instruments onboard the ship allow fluxes to be estimated for the whole expedition. Static stability is estimated from the Marine Atmospheric Emitted Radiance Interferometer (MAERI) instrument onboard Oden to fill missing data periods from the eddy correlation measurements, as well as to extend the observations of turbulent fluxes to the entire ASCOS expedition. The MAERI measured air temperature, viewing horizontally out from its position at $21 \mathrm{~m}$ on the port side of the ship, and the surface temperature, viewing down at the surface from the same position; since the same sensor is used for both, the temperature difference is not affected by systematic errors. These data were combined with the observed humidity, assuming a saturated surface with respect to the observed temperature, and wind speed from the ship's weather station to obtain the turbulent fluxes using the TOGA COARE bulk flux scheme, modified for Arctic sea-ice conditions (Persson et al., 2002). However, MAERI temperatures were sometimes affected by certain physical factors; when the ship was oriented so that the MAERI sensor viewed open ocean, rather than ice, it sometimes measured a higher temperature than over the adjacent ice surface, leading to an overestimation of the heat fluxes. Also, when the wind direction was from Oden's starboard side, across the ship, the MAERI, being located on the port side, may have observed too high air temperatures due to the heat plume from the ship; then the sensible heat flux is likely underestimated.

\subsection{Analysis method}

The first MMCR range gate in the vertical with a return power below the radar sensitivity demarcates the cloud top, while the highest observed ceilometer cloud base below cloud top is considered as the base for this layer. Both ceilometers are used for consensus. Median cloud boundaries were computed from a 2 min window following each scanning radiometer measurement and a 10 min window following each radiosonde release. For the analysis of cloud bulk properties (LWP, IWP) and the radar Doppler moments, the same time windows were used to derive median values. Considering the persistence of low-level Arctic clouds (Shupe et al., 2011), the assumption that the median cloud layers are in steady state over the above applied time-windows is reasonable. Median boundaries are used, instead of the mean, in order to reduce the effect of outliers (Sedlar et al., 2011), as may occasionally occur with only slightly less than complete overcast conditions, or when a second cloud layer emerges within the time window following thermodynamic profiles.

Profiles of $\Theta_{\mathrm{E}}$ are used to define the cloud-driven turbulent mixed layer; depending on whether this layer extends down to the surface or not, the cloud is classified as either coupled or decoupled, respectively. If a cloud-driven mixed layer is not observed, then the cloud is classified as "stably stratified". Note that stably stratified clouds are also not connected to the surface; here the word decoupled refers only to cases with a cloud-driven mixed layer. Two sets of data are used; either using the radiosoundings directly or combining the higher frequency scanning radiometer temperature profiles with interpolated specific humidity from the soundings. While the radiosonde equivalent potential temperature data are more accurate, they have temporal limitations. On the other hand, while the interpolation of specific humidity is a limitation for the scanning radiometer data, it allows using a higher temporal resolution and increases the number of profiles included in the study. The classification of vertical thermodynamic structure of the clouds based on the scanning radiometer profiles is in good agreement with the results derived from the radiosonde data set. Therefore, the majority of the results in this study are based on the scanning radiometer, while for other information the radiosonde data are used (e.g., humidity and wind).

An algorithm was developed to identify the main temperature inversion in the layer extending above cloud base until 

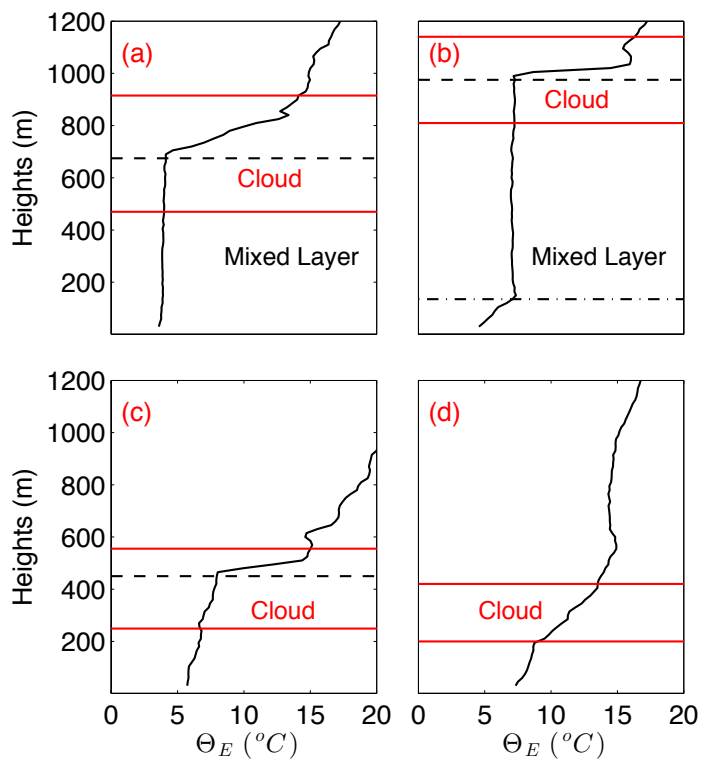

Figure 2. Example profiles of scanning radiometer equivalent potential temperature $\left(\Theta_{\mathrm{E}}\right)\left({ }^{\circ} \mathrm{C}\right)$ vertical profiles from four ASCOS cases: (a) coupled cloud (DoY 240, 20:16:47 UTC), (b) decoupled cloud (DoY 239, 16:51:47 UTC), (c) stable cloud (with inversion identified around cloud top) (DoY 217, 16:45:00 UTC), (d) stable cloud (no inversion around cloud top) (DoY 251, 02:43:13 UTC). Red lines indicate the respective cloud boundaries observed at profile time. The inversion base height is shown as the black dashed line. The black dashed-dotted line indicates the decoupling height. The layer between dashed and dashed-dotted, or the surface, is defined as the mixed layer.

$100 \mathrm{~m}$ above cloud top, by applying thresholds to the $\Theta_{\mathrm{E}}$ profiles. A quasi-constant $\Theta_{\mathrm{E}}$ from the inversion base down to the surface is taken to indicate coupling, whereas a decrease towards the surface below the cloud indicates a local stable layer and hence decoupling. The height at which the $\Theta_{\mathrm{E}}$ has decreased by $0.5^{\circ} \mathrm{C}$, compared to the cumulative mean value of the layer above, is considered to be the decoupling height. This threshold was selected to optimize between accuracy and reliability, given the vertical variability of the observed temperature, especially in the soundings, and the results were reasonably insensitive to small changes in the threshold. The layer between the cloud base and the decoupling height will be referred as the sub-cloud mixed layer (SCML). Both coupled and decoupled clouds will be often referred as neutrally stratified clouds, referring to the gradient $\Theta_{E}$ profile within the cloud layer. If the gradient of $\Theta_{\mathrm{E}}$ is positive through the whole cloud layer, it is classified as a stably stratified or stable cloud. Moreover, profiles with no inversion near cloud top were reexamined by estimating the $\Theta_{\mathrm{E}}$ gradient from cloud top to cloud base. These profiles were found to have large gradients and so these cases are also considered to be stable clouds. To illustrate qualitatively the differentiation of the categories using the $\Theta_{\mathrm{E}}$ profiles, examples are given in
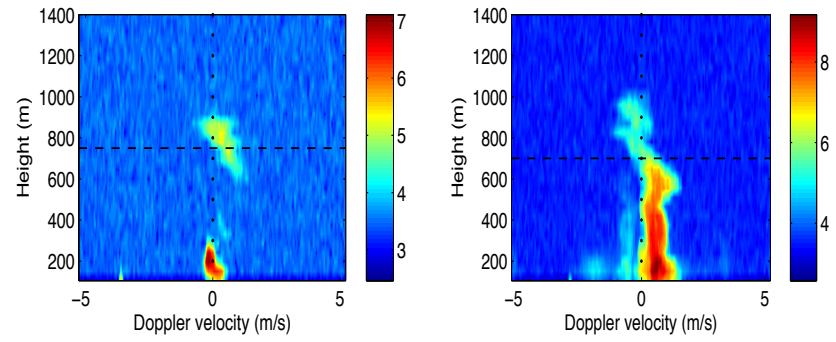

Figure 3. Spectrographs for two ASCOS snapshots: (a) DoY 241, 19:11:52 UTC: The cloud top median height observed by the MMCR is $960 \mathrm{~m}$ and the median cloud base height observed by the ceilometer is $90 \mathrm{~m}$. We estimate the upper cloud base at $750 \mathrm{~m}$ from the spectrograph. (b) DoY 237, 10:11:40 UTC: The cloud top median height is $1095 \mathrm{~m}$ and ceilometer median cloud base height is $140 \mathrm{~m}$. We estimate the real base at $700 \mathrm{~m}$. The horizontal black dashed lines indicate the qualitatively derived cloud base heights. Colors show the relative frequency distribution (logarithm of reflectivity counts) of spectral density of Doppler velocity with height. Positive (negative) values represent downward (upward) motion. Zero values are highlighted with dots.

Fig. 2 for coupled (Fig. 2a), decoupled (Fig. 2b) and stable clouds with a main inversion identified close to the cloud top (Fig. 2c) and with no main inversion identified (Fig. 2d).

Only profiles with a cloud top below $1500 \mathrm{~m}$, a cloud base below $1200 \mathrm{~m}$ and a cloud thickness larger than $135 \mathrm{~m}$ (three radar gates) are included in the analysis. It is not possible to evaluate how these choices affect the results, since these limits are set by real limitations in the instruments that cannot be freely varied. In addition, profiles where cloud thickness is greater than $700 \mathrm{~m}$ are assumed to be two cloud layers with precipitation falling from the upper cloud and where the ceilometer fails to penetrate the lower cloud to detect the upper cloud base; the choice of this threshold is based on relative results by Shupe et al. (2013), who included only single cloud layers in their analysis. For some of these cases, it is possible to estimate the upper cloud base from spectrographs. Two examples are shown in Fig. 3. For these cases, the cloud top detected by the MMCR is the top of the upper cloud, whereas the existence of a lower dense cloud prevents the ceilometer from measuring the corresponding upper cloud base height. In the cases in Fig. 3, the cloud top and base derived directly from the instruments is $960 \mathrm{~m}$ and $90 \mathrm{~m}$, and $1095 \mathrm{~m}$ and $75 \mathrm{~m}$, respectively, but from the spectrographs we could infer that there are two cloud layers present and the base of the upper clouds are around $750 \mathrm{~m}$ and $700 \mathrm{~m}$, respectively. These are identified as the levels where the Doppler velocities become systematically large and positive, indicating only falling hydrometeors and an absence of liquid cloud droplets, assuming that the latter are small and have negligible (near $0 \mathrm{~m} \mathrm{~s}^{-1}$ ) fall velocities. Hence the height where significant radar power crosses the zero velocity line is indicative of the liquid base height. 
Using radiosonde profiles for the classification, the same cloud thickness criteria are applied, since they are due to the MMCR, but a less strict cloud top criterion is applied, including cloud returns up to $3000 \mathrm{~m}$. The less strict cloud-top criterion for the radiosonde profiles allows more cases to be included and is consistent with the aim to analyze stratocumulus. It is chosen because of the shorter time-series that this instrument provides and the need to include as many profiles as possible in our analysis.

Applying the above criteria, 3436 out of the total available 8261 scanning radiometer profiles are considered, or $42 \%$ data coverage. For almost $40 \%$ of the available ASCOS profiles, a proper low cloud top, as defined above, was not detected by the radar due to the presence of deep precipitating weather systems (see Fig. 1), whereas around $18 \%$ fail to pass the geometrical restrictions. Hence, considering only the times when deep weather systems were not present, the algorithms described above captures roughly two-thirds of the available data. As a comparison, 87 out of the 145 $(\sim 60 \%)$ radiosonde profiles pass the above criteria for similar reasons.

To investigate the liquid and ice water cloud properties that characterize each cloud state, single cloud-layer profiles had to be selected, since the derived LWP is a vertically integrated quantity; the vertical distribution of the liquid is unknown, and with multiple cloud layers it becomes difficult to partition the liquid among layers. For this particular purpose, profiles where the ceilometer detected more than one cloud base or the MMCR detected more than one cloud top were rejected. Out of the 3436 scanning radiometer profiles that are used for the main analysis, slightly less than half, or 1611, represent single cloud layers and are used for the analysis of cloud liquid and ice characteristics.

\section{Results}

\subsection{Cloud states}

Considering results based on the scanning radiometer alone, $40 \%$ of the cases are decoupled while $28 \%$ are coupled and $32 \%$ are considered stable (Fig. 4, dark blue). The corresponding results from the radiosonde profiles are $46 \%$ decoupled, $23 \%$ coupled and $31 \%$ stable. The somewhat higher (lower) fraction of decoupled (coupled) clouds for the radiosondes may be due to the inclusion of higher cloud tops; as will be shown later, higher clouds are more likely to be decoupled than lower ones. Considering the limited number of soundings available, the agreement is reasonable and supports the use of the scanning radiometer profiles for the analysis.

Figure 4 also shows the relative frequency distributions (RFDs) of coupled, decoupled and stable clouds for each period of ASCOS (see Sect. 2.1). Many deep precipitating weather systems advected overhead from the beginning of

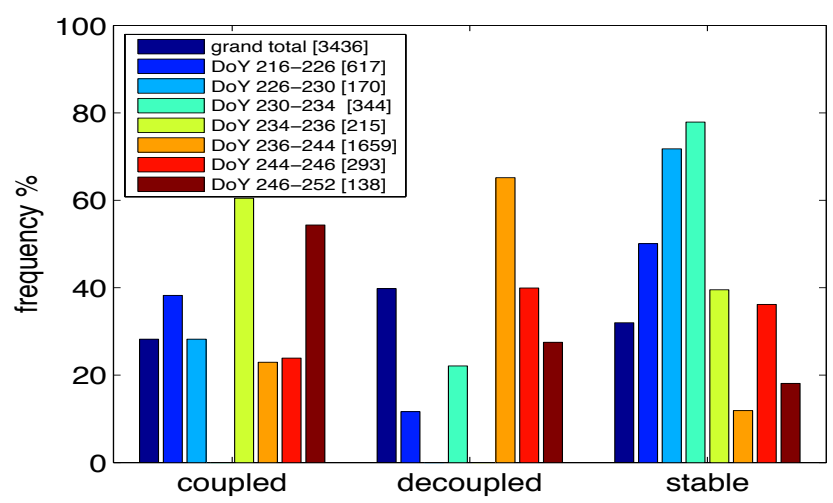

Figure 4. Relative frequency distribution (RFD) of cloud state occurrence for each period of ASCOS. The number in the brackets indicates the total number of scanning radiometer profiles analyzed for each period of ASCOS (see Sect. 2.3 for a discussion on period characteristics).

the expedition until the end of the 2nd ice drift period, and during the transition to the end of ASCOS (Fig. 1). Hence there were only short and scattered occurrences of low stratocumulus during these periods, which is why few profiles are included here.

From the beginning of ASCOS until the end of the 2nd period of the ice drift, either stable or coupled clouds dominate when low-level stratocumulus are intermittently present; nearly $80 \%$ of the profiles satisfying the geometric cloud constraints described above during DoY 216-230 contain low clouds with tops below $500 \mathrm{~m}$. The high fraction of stable clouds during this time is likely due to optically and geometrically thin clouds; this will be investigated below. In the cases where a cloud-driven mixed layer is observed, the proximity of these clouds to the surface makes it easier for the cloud-generated motions to interact with surface-generated turbulence (Shupe et al., 2013), which we speculate is the reason why decoupled cases are rare during these early periods of ASCOS.

During the second period of the ice drift (DoY 230-234), higher clouds with tops above $800 \mathrm{~m}$ in between the deeper precipitating systems are observed, which are either decoupled or stable; however the latter is still the dominant state. During the third period of the ice drift (DoY 234-236), the observed cloud states are either coupled or stable, but now with coupled being the most frequent. This period is dominated either by very low clouds or fog $(95 \%$ of the profiles have a cloud top below $400 \mathrm{~m}$ ).

The fourth period of the ice drift (DoY 236-244) provides almost half of the profiles included in this study. This is the longest period and also the one that was examined by Shupe et al. (2013) and Sedlar and Shupe (2014) to study the cloud-surface interactions and vertical velocity characteristics during ASCOS. The persistent stratiform layer (Fig. 1) is often decoupled, but intermittently connects thermodynam- 
ically with the surface. Stable clouds are observed in only $\sim 10 \%$ of these profiles. Taking only the neutrally stratified profiles into account, $74 \%$ are found to be decoupled and $26 \%$ coupled; this is in very good agreement with the occurrence statistics found in Shupe et al. (2013) and Sedlar and Shupe (2014).

During the fifth period (DoY 244-246), neutrally stratified clouds still dominate, although a considerable portion $(\sim 35 \%)$ of stable cases are also observed. At the beginning of this period the stratiform cloud conditions from the previous period persist, but are gradually decreasing in depth and height, becoming tenuous, and at some points even dissipating (Fig. 1). Finally, from the transit period away from the ice drift, few profiles are included because of the occurrence of several deep precipitating weather systems. Most profiles are derived from DoY 246-248, when a low stratiform cloud layer is observed, and from a few hours during DoY 249 and 251, when a very low tenuous cloud is apparent in the MMCR reflectivity (Fig. 1).

To summarize, the RFD of coupled, decoupled and stable cloud profiles derived either from the scanning radiometer (Fig. 4) or the radiosonde (not shown) reveals that neutrally stratified clouds (coupled plus decoupled) are more frequent during ASCOS than stable clouds. Yet, in the majority of the neutral cloud cases the cloud-generated turbulence does not mix with the boundary layer below down to the surface, and the cloud remains decoupled. This is generally in agreement with Sedlar and Shupe (2014) and Shupe et al. (2013), although the latter suggest an even higher fraction of the neutrally stratified clouds to be decoupled; as shown above, this difference is due to the different samples' size, while the use of different method does not seem to affect the occurrence statistics.

The RFDs for cloud boundaries and cloud thickness are shown in Fig. 5. The distribution of cloud top (Fig. 5a) indicates that clouds with tops above $\sim 900 \mathrm{~m}$ are usually decoupled while those with tops below $\sim 500 \mathrm{~m}$ are coupled or stable. The frequency distribution for cloud base (Fig. 5b) shows that coupled and stable clouds have a cloud base below $\sim 200 \mathrm{~m}$ during more than $50 \%$ of their occurrences, whereas the decoupled cloud base distribution peak is much broader, between 400 and $800 \mathrm{~m}$. In addition, the RFD for cloud thickness (Fig. 5c) indicates that stable clouds are geometrically thinner than neutrally stratified clouds, whereas decoupled clouds are in general no thicker than the coupled clouds.

In summary, this analysis shows that stable clouds are geometrically thin and low, while neutrally stratified clouds are thicker with a tendency to have bases higher above the surface. However, decoupled clouds appear higher up in the atmosphere than coupled clouds; these results provide hints at the mechanism explaining the different cloud classes. While turbulence is practically always generated at the surface by mechanical mixing, unless very weak winds prevail, strong radiative cooling at cloud top normally gives rise
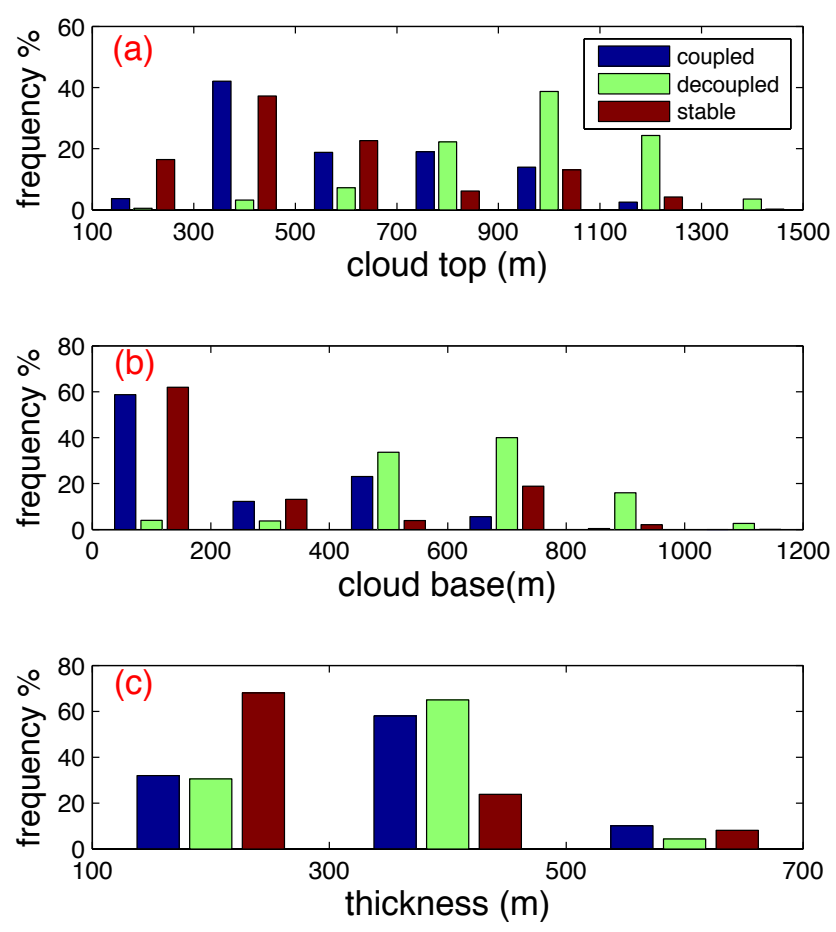

Figure 5. RFDs of (a) cloud top height (m), (b) cloud base height (m) and (c) cloud thickness (m) for coupled (blue), decoupled (green) and stable (red) cloud states. Bin size is $200 \mathrm{~m}$ and centered in the interval.

to buoyancy-generated turbulence inside the cloud layer. In cases when the cloud layer is sufficiently close to the surface, the two layers may interact, leading to a continuously coupled state. On the other hand, when cloud layers are displaced higher, with cloud tops above $900 \mathrm{~m}$, the in-cloud turbulence generated at the cloud top usually does not penetrate to the surface-based mixed layer and thus becomes independent of the surface conditions; the cloud state is decoupled. An exception to this description is a number of low clouds that are not mixed at all (stable cloud states); these are about half of the lowest and thinnest clouds, with cloud bases $<\sim 200 \mathrm{~m}$ and thicknesses $<\sim 300 \mathrm{~m}$. This indicates that these thin clouds do not cool sufficiently to space at the top, probably because they are either too optically thin or the liquid water content is distributed rather homogenously across the cloud layer, but also that the surface generated turbulence is often too weak to mix clouds even when they lie below a few hundred meters.

The relationship between cloud boundaries and the depth of the SCML is further explored; it is found that the depth of the SCML increases as cloud base and top heights increase (not shown). Yet, SCML depths are almost indifferent to cloud thickness and increase only slightly with increasing cloud thickness; however, it must be recalled that the range of thickness is similar for nearly all low-level cloud mixing states (see Fig. 5c). The above general relationships were also 

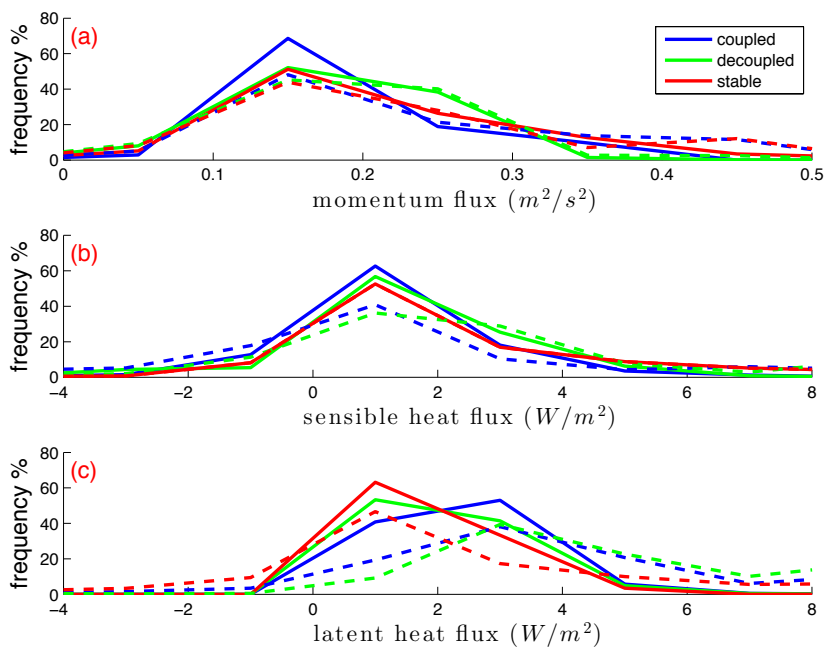

Figure 6. RFDs of (a) friction velocity $\left(\mathrm{m} \mathrm{s}^{-1}\right)$ representing momentum flux, (b) sensible heat flux $\left(\mathrm{W} \mathrm{m}^{-2}\right)$ and (c) latent heat flux $\left(\mathrm{W} \mathrm{m}^{-2}\right.$ ) for coupled (blue), decoupled (green) and stable (red) clouds. Solid lines represent fluxes estimated from sonic anemometers while dotted lines are the bulk fluxes; see Sect. 2 for a description on flux calculations.

observed by Shupe et al. (2013), although for a shorter period, hence the results are not shown here.

\subsection{Surface fluxes}

The results in the previous section indicate that cloudinduced turbulence determines coupling state, however, intuitively it would be reasonable to expect larger surface fluxes to facilitate coupling to the surface. To examine the influence of the turbulent surfaces fluxes on the cloud coupling state, RFDs of momentum, sensible and latent heat fluxes for the three cloud coupling states are shown in Fig. 6. Upward fluxes are positive; momentum flux is represented by the friction velocity which is always positive. Turbulent heat fluxes are generally very small while the momentum fluxes can be substantial (Tjernström et al., 2012). A comparison of the two time series during times when they overlap (not shown) revealed relatively good agreement for the momentum and sensible heat fluxes, whereas the latent heat fluxes exhibited larger differences; see Sect. 2.2 for a discussion.

RFDs for momentum flux (Fig. 6a) show no significant difference among the three cloud states, although the decoupled state has a broader peak over slightly higher values. This is contrary to expectations; a larger momentum flux means more mechanical mixing and, if it was important for the cloud state, less likely to be present in a decoupled state. These distributions indicate that mechanical mixing is indeed not a leading factor that determines coupling state. The same conclusion holds for the sensible (Fig. 6b) and latent (Fig. 6c) heat fluxes, suggesting that surface turbulence is not responsible for cloud-surface coupling states and that these interac-
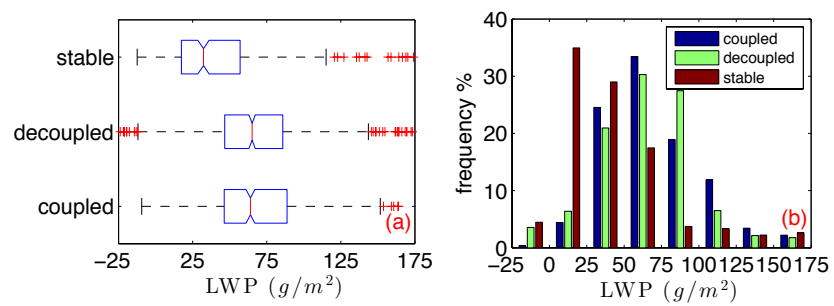

Figure 7. (a) Notched box-and-whisker plots and (b) RFDs of LWP $\left(\mathrm{g} \mathrm{m}^{-2}\right)$ for coupled, decoupled and stable single cloud layers. In (a), median values are indicated by the red solid line, edges of the box mark the lower and upper quartiles, whiskers represent the extent of the data that is 1.5 times the difference between the upper and lower quartile and crosses are outliers. Notches offer a rough guide to significance of difference of medians; the width of the notches is proportional to the interquartile range of the sample and inversely proportional to the square root of the size of the sample. The bin size in (b) is $25 \mathrm{~g} \mathrm{~m}^{-2}$ and centered in the interval. Negative values are due to the instrument uncertainty of $25 \mathrm{~g} \mathrm{~m}^{-2}$.

tions are thus mainly driven by the cloud. This is in agreement with the results from Shupe et al. (2013).

\subsection{Cloud water properties}

Cloud water properties are analyzed from single cloud-layer cases only; see Sect. 2.3. Of these $52 \%$ were decoupled, $31 \%$ coupled and $17 \%$ were stable. The lower fraction of stable cases suggests that these are often present during occasions of multiple cloud layers. However, the ratio between the two mixing states compares favorably to the results from the whole period and those from only soundings.

The results in Fig. 7a are shown as box-and-whisker plots, and in Fig. 7b as histograms. Negative (unphysical) LWP values included in the statistics are due to the LWP uncertainty of $\sim 25 \mathrm{~g} \mathrm{~m}^{-2}$ from the MWR instrument (see Sect. 2.2). Figure $7 \mathrm{a}$ reveals that the stably stratified cloud state is statistically different from neutrally stratified cloud states, since the LWP median $\left(\sim 32 \mathrm{~g} \mathrm{~m}^{-2}\right)$ is $\sim 50 \%$ smaller than the corresponding values for the latter states $\left(64-65 \mathrm{~g} \mathrm{~m}^{-2}\right)$; a student t-test confirmed the significance of this difference at the $95 \%$ confidence level. Hence, the initial hypothesis about the origin of the stable cases is supported; a cloud emits radiation as a blackbody when LWP is larger than $\sim 30-50 \mathrm{~g} \mathrm{~m}^{-2}$ (Stephens, 1978). Cloud LWPs for the stable state are often at or below this blackbody emissivity range, and it is likely that cloud-top radiative cooling, and hence buoyant mixing, is reduced. The two neutrally stratified cloud states exhibit no statistical difference, suggesting that LWP by itself does not determine coupling state.

Histograms of LWP for the three cloud types (Fig. 7b) also indicate that the stable cloud states in most cases are optically thin; $72 \%$ of the stable cloud profiles have LWP observations below $50 \mathrm{~g} \mathrm{~m}^{-2}$. Note, however, that even for the clouds that contain enough liquid to be "blackbodies", the 

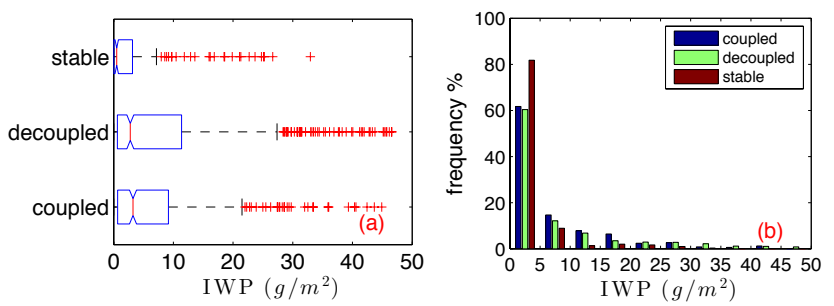

Figure 8. Same as in Fig. 7, but for ice water path (IWP) $\left(\mathrm{g} \mathrm{m}^{-2}\right)$ derived from radar power-law relationships. The bin size in (b) is $5 \mathrm{~g} \mathrm{~m}^{-2}$ and centered in the interval.

buoyancy-generation of turbulence depends on the differential cooling in the vertical. Thus, if liquid is homogeneously distributed across the cloud then, instead of generating turbulence and mixing, the whole cloud layer will cool. The RFDs for both neutrally stratified states have peaks between $50-80 \mathrm{~g} \mathrm{~m}^{-2}$; decoupled clouds have the RFD peak shifted slightly to higher values compared to the coupled clouds.

This result is contrary to that in Shupe et al. (2013), who found that coupled clouds tend to have more LWP than decoupled; the reason may be the larger sample in the present study. To investigate how the choice of a certain period of data affects the statistical results, we calculated the LWP statistics for the 4th period of ASCOS ice drift separately, the same period analyzed by Shupe et al. (2013), and compared to the remaining periods. Considering only this period, the median LWP for coupled clouds is $\sim 77 \mathrm{~g} \mathrm{~m}^{-2}$ and its 25th percentile is $\sim 58 \mathrm{~g} \mathrm{~m}^{-2}$, while for the remaining periods it is $\sim 58$ and $\sim 43 \mathrm{~g} \mathrm{~m}^{-2}$, respectively (not shown). This shows that coupled cases during a persistent and relatively thick stratocumulus deck (Fig. 1) analyzed in Shupe et al. (2013) contained relatively more liquid than during the other periods, indicating that the difference may lie in the differing time samples. This illustrates the importance of having long time series for this type of analysis.

The results for the IWP (Fig. 8) also show that stable clouds differ from the other two cloud types; stable cloud states have an IWP median around $\sim 0.5 \mathrm{~g} \mathrm{~m}^{-2}$, which is $4-6$ times smaller than that for the neutrally stratified cloud states, and frequently has zero IWP. The medians for the coupled and decoupled states are around $\sim 3.2$ and $\sim 2.7 \mathrm{~g} \mathrm{~m}^{-2}$, respectively. The fact that stable cases have an IWP close to zero indicates that these clouds are often not mixed-phase. Furthermore, some of these stable clouds are probably cases of fog, consistent with their lower cloud boundary statistics (see above).

\subsection{CCN concentrations}

Cloud formation depends on the presence of $\mathrm{CCN}$; moreover, the concentration of CCN strongly affects the optical properties of clouds and may impact on the cloud-induced turbulence. Figure 9 illustrates near-surface $\mathrm{CCN}$ concentrations

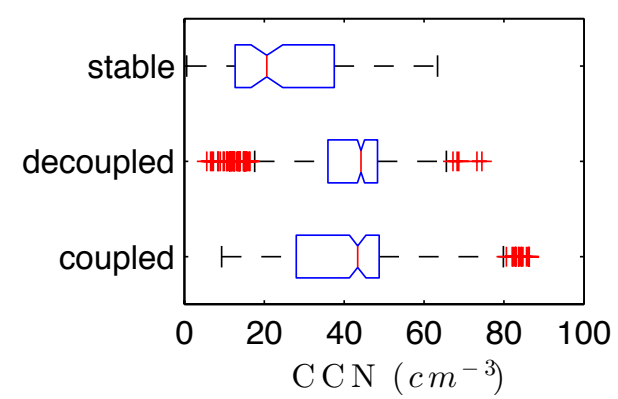

Figure 9. Notched box-and-whisker plot of CCN concentrations $\left(\mathrm{cm}^{-3}\right)$ for coupled, decoupled and stable cloud layers. CCN concentrations are measured from ship level (see Martin et al., 2011).

observed during coupled, decoupled and stable states. The available CCN data corresponds to the period between DoY 228-252, while during that time there are several short periods where no data are available at all (e.g., due to pollution contamination by ship exhaust; see Martin et al., 2011). As a result, it is possible to match a $\mathrm{CCN}$ concentration to a cloud state for only $25 \%$ of the total scanning radiometer profiles. Also note that $\mathrm{CCN}$ is observed near the surface and that the observations may not necessarily be representative for conditions in the cloud layer.

The median CCN concentration (Fig. 9) for stably stratified clouds is $\sim 21 \mathrm{~cm}^{-3}$, whereas for neutrally stratified cases the medians are twice as large, $\sim 43-44 \mathrm{~cm}^{-3}$. The low $\mathrm{CCN}$ concentrations explain the limited liquid amounts present in stable clouds, thus providing additional support to the hypothesis that stable clouds are optically thin; also see Mauritsen et al. (2011) that analyzed the effects of CCN concentration on the optical properties of Arctic low-level clouds.

\subsection{Vertical structure}

To investigate the structure and phase of the clouds, RFDs of radar reflectivity as a function of height are shown in Fig. 10. These results are shown on a scaled vertical axis, which, by necessity, are slightly different for the three different cloud states; each layer is scaled independently. For coupled clouds, $z_{n}=-1$ represents the MMCR's first range gate, $z_{n}=0$ is the cloud base and $z_{n}=1$ the inversion base. Stable cases are normalized in similar manner, except that $z_{n}=1$ is at the cloud top, since a temperature inversion associated with the cloud top is not always present; note that reflectivities above the cloud top are present in Fig. 12c, as a stricter definition on radar reflectivity was used here to identify cloud boundaries, while the full reflectivity profile was used for the statistics. Decoupled clouds have three layers; the first range gate is at $z_{n}=-2$ while $z_{n}=-1$ is the decoupling height, $z_{n}=0$ the cloud base and $z_{n}=1$ the inversion base. Heights above $z_{n}=1$ (the free troposphere) are also 

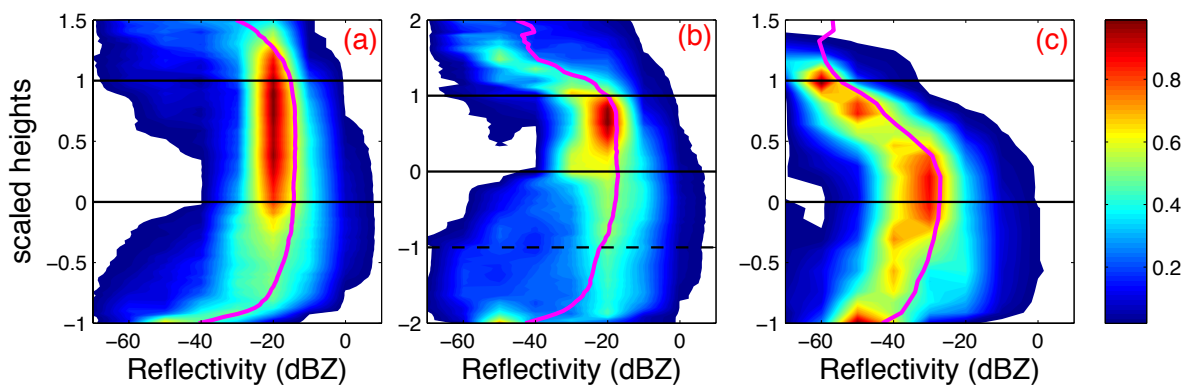

Figure 10. RFD contour plots of radar reflectivity (dBZ) for (a) coupled, (b) decoupled and (c) stable clouds; magenta profiles are the medians. Heights are normalized: for (a) coupled clouds, $z_{n}=-1$ is the first range gate, $z_{n}=0$ is cloud base and $z_{n}=1$ is the main inversion base; for (b) decoupled clouds, $z_{n}=-2$ is the first range gate, $z_{n}=-1$ is the decoupling height, $z_{n}=0$ is cloud base and $z_{n}=1$ is main inversion base; for (c) stable clouds, $z_{n}=-1$ is the first range gate, $z_{n}=0$ is cloud base and $z_{n}=1$ is cloud top; reflectivity values above cloud top $\left(z_{n}=1\right)$ for (c) occur because stricter reflectivity thresholds were applied to identify cloud boundaries, while the full reflectivity profiles were used to compute the histogram statistics. Frequencies are normalized by unity (unity indicates the maximum frequency of all levels).
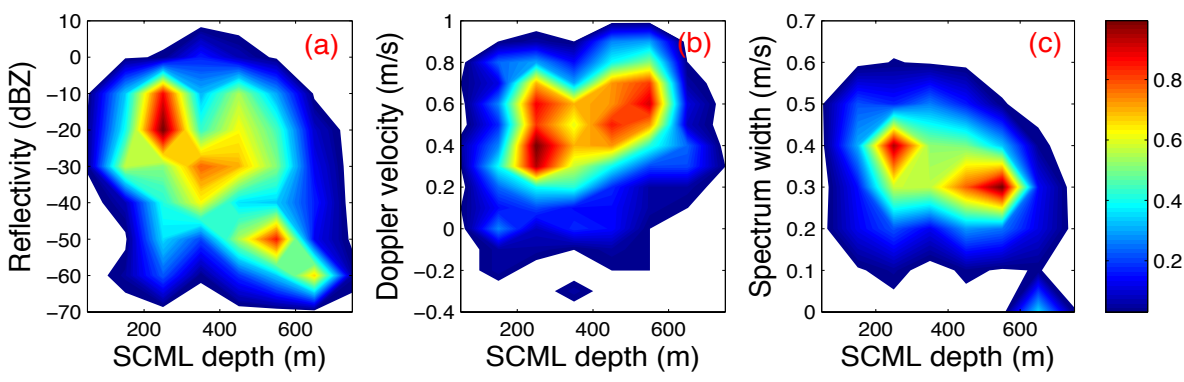

Figure 11. 2-D RFD contour plots of (a) radar reflectivity (dBZ), (b) Doppler velocity $\left(\mathrm{m} \mathrm{s}^{-1}\right)$ and (c) spectrum width (m $\left.\mathrm{s}^{-1}\right)$ at the decoupling height, in relationship to the sub-cloud mixed layer (SCML) depth (m). Frequencies are normalized by unity.

scaled by the thickness of the layer below, since there is no other obvious scaling.

For coupled clouds (Fig. 10a) the range of reflectivity values extends from $-40 \mathrm{dBZ}$ to $-5 \mathrm{dBZ}$, with a maximum frequency around $-20 \mathrm{dBZ}$, throughout the whole cloud, and almost the whole sub-cloud layer although the spread is larger here. A rapid decrease is only observed close to the surface, where evaporation or sublimation of precipitation takes place. Above the inversion base, the maximum RFD remains constant to about $z_{n} \approx 1.3$, suggesting that the top of these clouds usually extend into the inversion layer (cf. e.g., Sedlar and Tjernström, 2009; Sedlar et al., 2012).

Decoupled clouds (Fig. 10b) have a similar structure to the coupled cases inside the cloud, but exhibit a larger spread in reflectivity below cloud base. The reflectivities of the layer between inversion base and cloud base extend from $-40 \mathrm{dBZ}$ to $-5 \mathrm{dBZ}$, whereas the values of the sub-cloud layer show an even larger spread especially towards the smaller values (down to $-65 \mathrm{dBZ}$ ). The RFD of the depth of the SCML (not shown) revealed that it often varies between 200-600 m; thus, larger variability in the sub-cloud layer reflectivity (Fig. 10b) may be due to different features or characteristics of the decoupled cloud and/or sub-cloud layers depending upon SCML depth.

The stable cases (Fig. 10c) are generally characterized by lower reflectivity compared to the coupled cases. In the lower half of the cloud, reflectivity extends between $-50 \mathrm{dBZ}$ and $-15 \mathrm{dBZ}$, with a maximum frequency around -40 to $-30 \mathrm{dBZ}$. Below cloud base, the decrease in magnitude with decreasing height is more pronounced than for coupled cases; the reflectivity is reduced by $\sim 10 \mathrm{dBZ}$ already at $z_{n} \approx-0.3$, although the width of the distribution increases, explaining the more gradual change in the median. In the upper half of the cloud, reflectivity decreases rapidly with height. The in-cloud reflectivity values are often well below $-17 \mathrm{dBZ}$, a general upper limit of cloud droplet-only returns (Frisch et al., 1995), supporting the hypothesis that stable clouds are not associated with appreciable precipitation.

In an attempt to investigate how the depth of the decoupled sub-cloud layer correlates with the vertical structure of precipitation, we use the relationships between the three radar moments at the decoupling height and the depth of the SCML (Fig. 11). Figure 11a shows that reflectivity at the decoupling height decreases gradually as the mixed layer deepens. For depths greater than $500 \mathrm{~m}$, a distinct peak in the RFD 



Figure 12. Same as Fig. 10 but for (a) clouds decoupled less than $450 \mathrm{~m}$ below cloud base and (b) clouds decoupled more than $500 \mathrm{~m}$ below cloud base.

is apparent at very small reflectivities $(<-50 \mathrm{dBZ})$. Likewise, the RFD of Doppler spectrum width (Fig. 11c) also shows a decrease in Doppler velocity variance for SCML depths $>\sim 300 \mathrm{~m}$. However, the Doppler velocity distribution (Fig. 11b) at the decoupling height shows a slight tendency to increase for SCML $>\sim 400 \mathrm{~m}$. This result appears to be inconsistent with the other two radar moment distributions with SCML depth, as decreasing reflectivity and reduced spectrum width tend to suggest a more homogeneous hydrometeor distribution of generally smaller sizes. One possible explanation is that decreasing reflectivity and spectrum width are affected by decreasing concentration of precipitation, e.g., caused by sublimation of precipitation occurring in the deeper SCMLs, but it is very difficult to de-convolve from the strong effect of size. Nevertheless, all radar moments show a bimodality in RFD for the primary SCML depths observed. To get a clearer distinction of the conditions that drive the decoupling at different depths, we separate the decoupled clouds in two sub-categories: those with a SCML depth less than $450 \mathrm{~m}$ and those with a SCML deeper than $500 \mathrm{~m} ; 60 \%$ and $30 \%$ of the total decoupled profiles respectively; clouds with a shallower SCML hence occur twice as often as clouds with a deeper SCML. Considering that increasing cloud boundaries correspond to increasing SCML depths (Sect. 3.1), the first category includes low decoupled clouds, whereas the latter includes some of the highest clouds observed.

In Fig. 12, the reflectivity for decoupled clouds is shown again, but now divided into the two categories. The decoupled clouds with the shallower SCML (Fig. 12a) have a very similar structure to the coupled clouds (Fig. 12a). On the other hand, decoupled clouds with a deeper mixed layer (Fig. 12b) differ substantially from all the other cases: the maximum occurrence frequency close to the inversion base is around $-20 \mathrm{dBZ}$, same as for the coupled and decoupled clouds with shallow SCML, but near cloud base it decreases to $-30 \mathrm{dBZ}$. This is the only case where a decrease inside the cloud layer is observed, suggesting that these clouds have little ice, such that the reflectivity profile within the cloud is actually dominated by the liquid. Furthermore, in the sub- cloud layer, reflectivity distribution is bimodal (Fig. 12b). In some cases it remains constant through cloud and upper subcloud layers, very similar to coupled and decoupled cases with a shallower SCML; this branch in the RFD however decreases and vanishes closer to the surface. The lack of values below the decoupling height suggests that these profiles get decoupled around $100 \mathrm{~m}$, the lowest vertical range gate of the MMCR. For the other mode, there is also a decrease with decreasing height, from values $<-40 \mathrm{dBZ}$ below cloud base until the decoupling height where the reflectivity minimum is reached, approaching $-60 \mathrm{dBZ}$. This illustrates the large potential impact on hydrometeors by evaporation/sublimation, when precipitation falls through a relatively deep sub-saturated layer below the cloud base.

Next the thermodynamic structures of the different (now four) cloud states are analyzed. We did not find any relationship between cloud states and either cloud top, cloud base or surface temperatures (not shown), so only the gradients of potential temperature profiles are shown in Fig. 13. Note, these are gradients of $\Theta$ profiles and not $\Theta_{\mathrm{E}}$, on which the separation of coupled, decoupled and stable state was based. Through the definition of $\Theta_{\mathrm{E}}$, an increase in $\Theta$ across a layer could be compensated by a decrease in $Q_{\mathrm{v}}$ leading to a constant $\Theta_{E}$; hence, a thermodynamically coupled case as defined using $\Theta_{\mathrm{E}}$ could appear decoupled when using the $\Theta$ profile. Figure 13, showing the statistics of the $\Theta$ gradient profiles with respect to normalized height (same as for radar reflectivity), reveals that this does not occur here.

In the coupled cases (Fig. 13a), the $\Theta$ gradient is slightly larger than zero in the cloud, consistent with the release of latent heat in the cloud interior, and remains almost constantly near-zero in the sub-cloud layer until the surface, where it increases only slightly. In both the decoupled classes, two separate layers below the cloud base are apparent. For the shallow SCML (Fig. 13b) category, the $\Theta$ gradient is near-zero from inversion base until the decoupling height, followed by a weak second inversion around the decoupling height and slightly stronger stability below. Near the surface, the $\Theta$ gradient is near-zero or even slightly negative, suggesting the existence of a turbulent surface layer.

For the decoupled state with a deeper SCML, however, the secondary inversion is substantially more pronounced (Fig. 13c). Here the layer above the decoupling height is also substantially less stable compared to the layer below. This difference in thermal structure explains the separation between decoupled cloud states with shallower or deeper SCML; it is actually a separation between states that are "weakly" or "strongly" decoupled. Thus from here and onwards we will examine four cloud states, using weakly and strongly decoupled, rather than "shallow" or "deep". In most stable cases (Fig. 13d), the near-surface structure is somewhat more neutrally stratified than aloft. The stratification is stable throughout the profile and these clouds are hence also disconnected from the surface. 

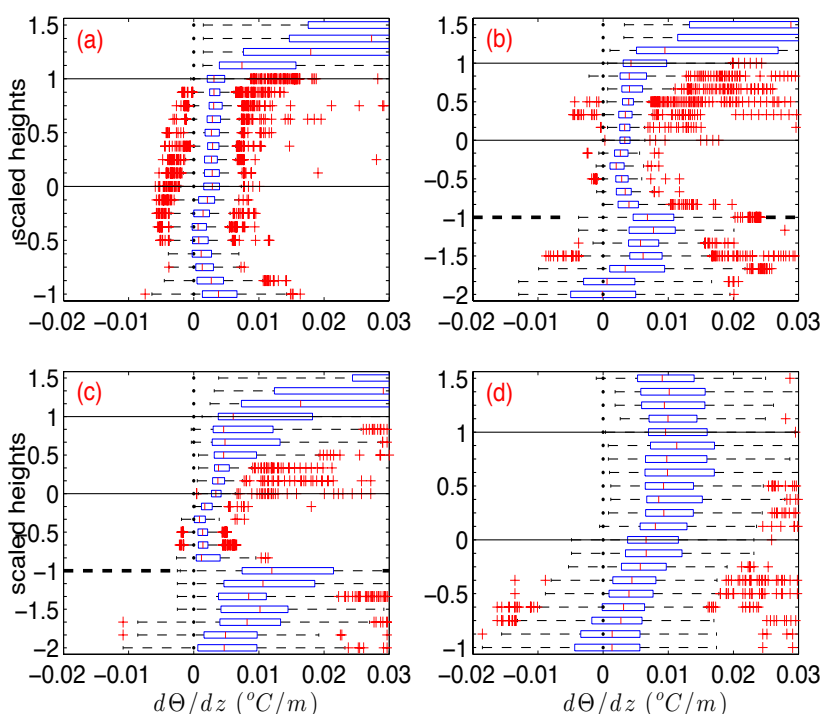

Figure 13. Box-and-whisker plots of scanning radiometer potential temperature gradient $\mathrm{d} \Theta \mathrm{d} z^{-1}\left({ }^{\circ} \mathrm{Cm}^{-1}\right)$ for (a) coupled, (b) weakly decoupled, (c) strongly decoupled and (d) stable clouds. The vertical scaling changes with cloud coupling state are same as described in Fig. 10. Zero values are highlighted with dots.
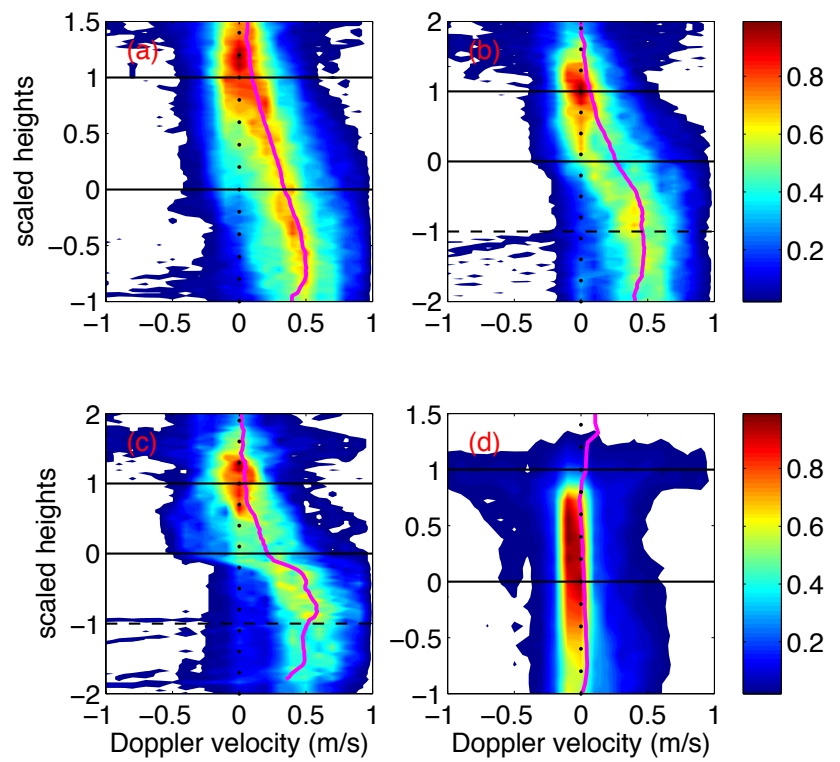

Figure 14. RFD contour plots of Doppler velocity $\left(\mathrm{m} \mathrm{s}^{-1}\right)$ for (a) coupled, (b) weakly decoupled, (c) strongly decoupled and (d) stable clouds; magenta profiles are the medians. The vertical scaling changes with cloud coupling state are same as described in Fig. 10. Zero values are highlighted with dots.

Figures 14 and 15 show normalized profile RFDs of mean Doppler velocity and spectrum width. The median velocity profile for coupled clouds (Fig. 14a) increases from the inversion base to close to the surface. In the cloud layer this behavior is expected as hydrometeor sizes increase through
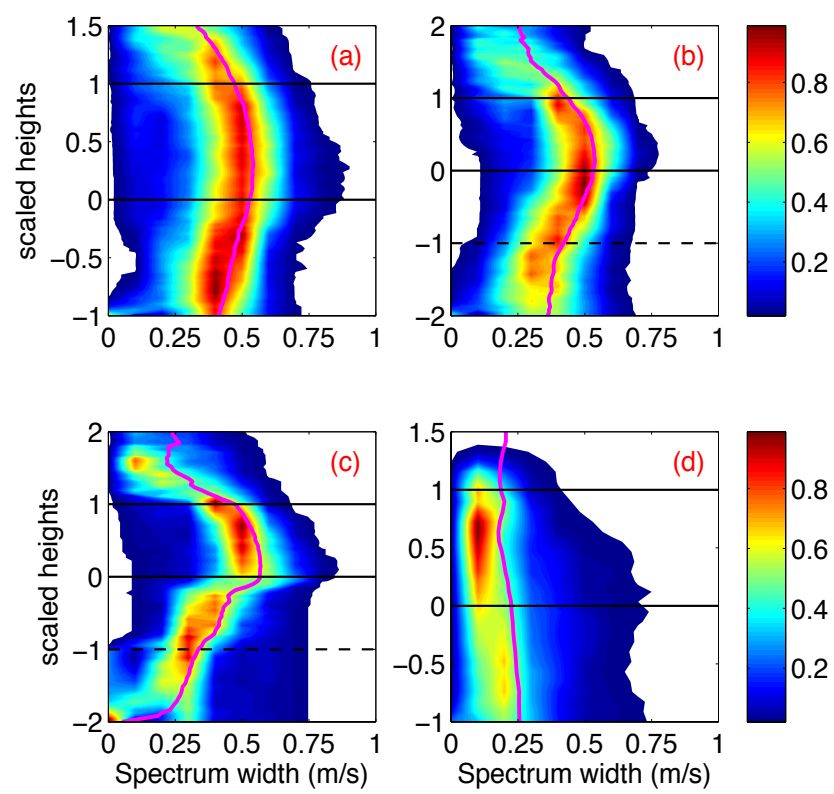

Figure 15. Same as Fig. 14, but for spectrum width $\left(\mathrm{m} \mathrm{s}^{-1}\right)$.

collisions and diffusional growth in the cloud interior, leading to larger hydrometeors with larger fall speeds. In the subcloud layer, further increases in mean Doppler velocity indicate a continued growth of the precipitation particles until approaching the surface. For the weakly decoupled state (Fig. 14b) this increase stops near the decoupling height and the Doppler velocity becomes constant below that level. For the strongly decoupled clouds (Fig. 14c) the Doppler velocity increases abruptly slightly below the cloud base and then becomes quasi-steady through the entire sub-cloud layer, including above and below the decoupling height. The RFD maximum frequencies for these cases are distributed around $0 \mathrm{~m} \mathrm{~s}^{-1}$ in the upper part of the cloud layer, suggesting that the returns in this area are from the cloud liquid droplets. Moving downward in the liquid layer the slowly increasing downward velocity is due to the fact that ice starts to become relatively more abundant and more important for the total backscatter. The quasi-constant Doppler velocity below the decoupling height is a similar feature for both decoupled states; the ceased acceleration of hydrometeors at the decoupling height could be connected with evaporation/sublimation occurring locally. The stable cloud states (Fig. 14d) exhibit a totally different vertical structure where Doppler velocity is distributed around zero throughout both cloud and sub-cloud layer. The median profile is close to zero suggesting no, or very small, mean vertical motions occur, in the cloud as well as the sub-cloud layer; this means that clouds in the stable state have negligible precipitation.

The Doppler spectrum width (Fig. 15) is generally increasing from inversion base down to cloud base for all cloud states, except for stable clouds (Fig. 15d), suggesting that with decreasing height, the variability in hydrometeor size 

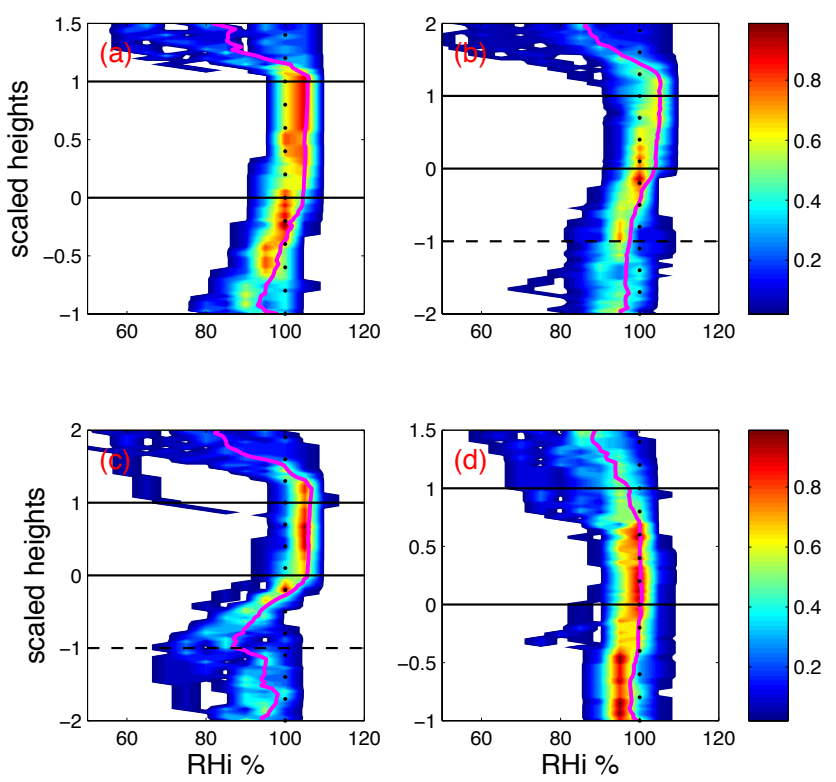

Figure 16. Same as Fig. 14, but for radiosonde relative humidity (\%) with respect to ice $\left(\mathrm{RH}_{\mathrm{i}}\right) .100 \%$ values are highlighted with dots.

also increases within the cloud layer. Below cloud base, spectrum width decreases downwards; this decrease is sharper for decoupled clouds and especially those that are strongly decoupled (Fig. 15c). The rather quick decrease in spectrum width below the cloud base in the latter cases is probably due to the fact that there is less ice precipitation in these clouds and/or the deeper SCML allows for increased sublimation of the smallest ice crystals, leading to a narrower Doppler spectrum.

Again, stable clouds (Fig. 15d) exhibit a completely different behavior than the other cases. The larger spectrum width frequencies are distributed around $0.2 \mathrm{~m} \mathrm{~s}^{-1}$ with an increasing spread towards higher values with decreasing height. These substantially smaller values in the cloud layer, compared to the neutrally stratified clouds, are an additional indication that stable clouds are often not mixed-phase and do not drive much turbulent mixing, while the slightly higher spread combined with near zero average velocities indicates that the lower part of the sub-cloud layer is slightly more turbulent than the cloud layer.

Profiles of relative humidity (with respect to ice, $\mathrm{RH}_{\mathrm{i}}$ ), specific moisture $\left(Q_{\mathrm{v}}\right)$ and wind speed $(U)$ (Figs. 16, 17 and 18 ) are analyzed from radiosoundings. Both $Q_{\mathrm{v}}$ and $U$ exhibited a significant scatter in absolute values, reflecting changes in air mass, so a scaling method was applied: the scaled variables $\left(U^{\prime \prime}, Q_{\mathrm{v}}^{\prime \prime}\right)$ are defined by subtracting the mean values in the layer between the surface and inversion base (or the cloud top for stable cases) from the actual values. $\mathrm{RH}_{\mathrm{i}}$ is in a sense already a scaled variable by definition and does not require any normalization. The RFDs of the two scaled variables and $\mathrm{RH}_{\mathrm{i}}$ are normalized with respect to height as previously.
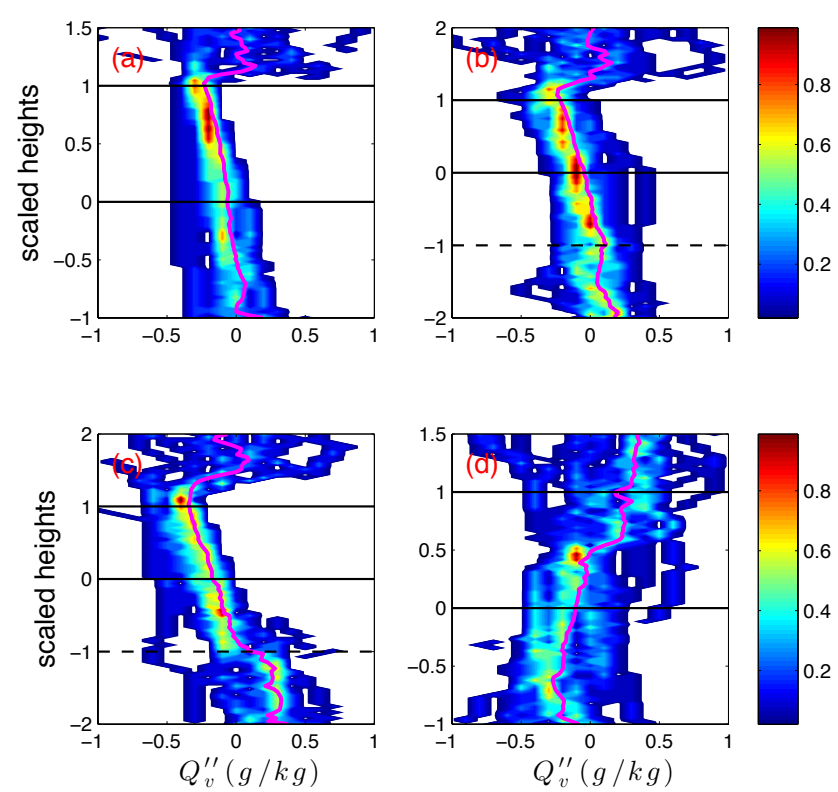

Figure 17. Same as Fig. 14, but for radiosonde scaled specific humidity $\left(\mathrm{g} \mathrm{kg}^{-1}\right)$. See Sect. 3.5 for details on the scaling method.

The maximum frequency of $\mathrm{RH}_{\mathrm{i}}$ is at or often above saturation in the cloud interior for all states (Fig. 16). This indicates that these clouds can support the coexistence of ice and liquid hydrometeors within the same volume, considering layer mean temperatures are often below freezing. In the coupled and stable states (Fig. 16a, d) $\mathrm{RH}_{\mathrm{i}}$ decreases below cloud base until the surface where it is sub-saturated. This decrease is also observed in the decoupled cases (Fig. 16b, c) but only down to the decoupling height; below that level it either remains roughly constant (Fig. 16b) or increases again (Fig. 16c). The decrease in $\mathrm{RH}_{\mathrm{i}}$ below the cloud base is the largest in the strongly decoupled cases (Fig. 16c) and a clear minimum is observed around the decoupling height, below $85 \%$. The generally decreasing $\mathrm{RH}_{\mathrm{i}}$ profile with decreasing height below cloud agrees with decreasing profiles of Doppler spectrum widths and reflectivities, indicating sublimation of falling ice crystals in the sub-cloud layer appears to be an ongoing process for the majority of the strongly decoupled cloud states.

Specific humidity (Fig. 17) is similar in all states, except for the stable cases (Fig. 17d), increasing with decreasing height from the inversion base until close to the surface. For decoupled states, the structure below the decoupling height is slightly different; specific humidity here is often quasiconstant, especially in the strongly decoupled state where this layer is substantially moister in water vapor than aloft (Fig. 17c); this moist environment could favor the formation of a lower secondary cloud layer. Both coupled and decoupled cloud states (Fig. 17a-c) show that moisture increases above the temperature inversion near cloud top (e.g., Sedlar and Tjernström, 2009; Sedlar et al., 2012), indicating a po- 
tential source of moisture for these cloud layers, by entrainment. While all neutrally stratified cases have the common feature of a general decrease in specific humidity with increasing height, the stable clouds (Fig. 17d) feature the exact opposite behavior; a general increase from near the surface to the cloud top. Only the layer close to the surface often appears slightly more moist; however, the sub-cloud layer is still less moist that the cloud layer and the air immediately above the cloud.

RFDs of wind speed profiles are given in Fig. 18. Wind speed is a highly variable component of the system; hence the RFDs appear more scattered. The median of coupled (Fig. 18a) and weakly decoupled clouds (Fig. 18b) are quite similar, with almost constant wind speed inside the cloud and an increase from the surface to the cloud base; for the coupled state, there is a very weak indication of a maximum at the cloud base, agreeing with vertical wind speed shear during coupled surface and cloud cases analyzed by Sedlar and Shupe (2014). In contrast, for the strongly decoupled state (Fig. 18c), the median increases below cloud base and reaches a maximum close to the decoupling height, and then decreases towards the surface. Although this structure consists of many uniquely varying profiles, it indicates the presence of low-level jets (LLJ) in some of them; the existence of these LLJs might explain the slightly higher momentum fluxes observed earlier in the decoupled cases (Fig. 6). The fact that the LLJ core occurs close to the decoupling height, where an inversion usually exists (see Fig. 13c), has been also observed in previous studies of nocturnal LLJs (Andreas et al., 2000; Jakobson et al., 2013). Finally, for the stable cloud state (Fig. 18d), median wind speed is similar to the coupled state, only the wind speed starts to decrease already from the cloud interior. However, the bimodal structure of the RFD in the sub-cloud layer indicates the potential presence of LLJs also here, with an occurrence of about half the time.

\section{Discussion}

Neutrally stratified clouds are usually mixed-phase, precipitating clouds, more frequently decoupled from the surface than coupled to it. In general, decoupled clouds are higher than coupled; the analysis revealed that clouds with tops below $700 \mathrm{~m}$ tend to get coupled to the surface, whereas those whose tops are above $900 \mathrm{~m}$ remain decoupled from it. No differences were observed in geometric thickness or condensed water properties between the two states.

Moreover, the surface fluxes are similar for both states, suggesting that the observed cloud thermodynamic state is not driven by changes in the magnitude, or sign, of the surface fluxes, in support of similar results in Shupe et al. (2013) and Sedlar and Shupe (2014). It is more likely that displacements downwards (upwards) of the cloud layer is the leading factor that results in coupling (decoupling), which would instead be related more to the synoptic scale weather pat-
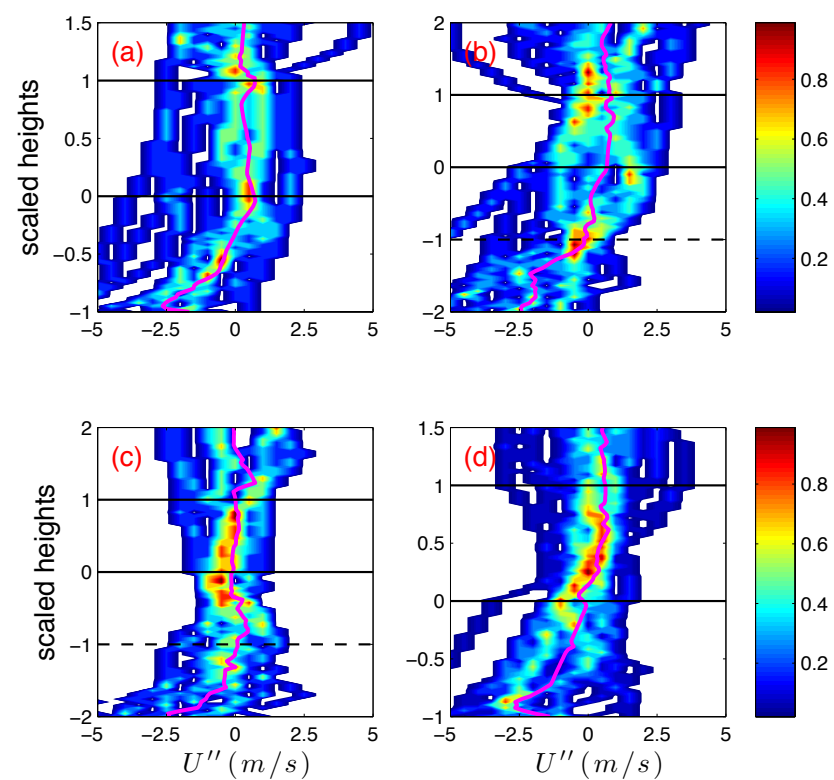

Figure 18. Same as Fig. 14, but for radiosonde scaled wind speed $\left(\mathrm{m} \mathrm{s}^{-1}\right)$. See Sect . 3.5 for details on the scaling method.

terns and advected thermodynamics (e.g., Sedlar and Shupe, 2014).

Decoupled clouds exhibit a differentiation in thermodynamic structure, depending on the depth of the SCML; those with SCML less than $450 \mathrm{~m}$ are disconnected from the surface by a weak inversion, whereas the clouds with SCML greater than $500 \mathrm{~m}$ are characterized by stronger inversions at the decoupling height. The weakly decoupled cases occur twice as often compared to the strongly decoupled.

Apart from the thermodynamic differences between the coupled and the two decoupled sub-categories, some microphysical differences were also observed. For the strongly decoupled cases, the radar reflectivity profiles exhibit a decrease inside the cloud, close to the cloud base and a bimodality in reflectivity distribution in the sub-cloud layer. One branch of the distribution indicates a large reflectivity decrease with decreasing height, suggesting that precipitation undergoes evaporation/sublimation in the sub-cloud layer. In contrast, for coupled and weakly decoupled cases the reflectivity remains almost constant throughout both cloud and sub-cloud layer.

In addition, in strongly decoupled cases the sub-cloud mixed layer is significantly drier; coupled and weakly decoupled RHi profiles decrease by only a few percent in the subcloud layer, while in strongly decoupled profiles it reaches a minimum around $85 \%$. Moreover, RHi reaches its minimum at the decoupling height and below that it increases again, suggesting that the vertical level at which the cloud gets disconnected from the surface could be impacted by evaporation/sublimation. This hypothesis is also supported by the fact that increasing mean Doppler velocity with decreasing 
height ceases at the decoupling height in both decoupled subcategories, which suggests that the hydrometeors do not grow below that level; on the contrary, in coupled cases the hydrometeors continue growing through the whole sub-cloud layer.

Harrington et al. (1999) and Stevens et al. (1998), using modeling tools, suggest that evaporation can promote decoupling, by cooling the sub-cloud layer and stabilizing the atmosphere. Based on ASCOS observations, it seems unlikely that such processes can be the primary reason driving the decoupling, since evidence of sublimation was mainly found for strongly decoupled clouds, about $1 / 3$ of all the total decoupled profiles. Yet, we speculate that evaporation/sublimation may explain why decoupling is amplified in these cases; for example, a strongly decoupled case may occur because of the existence of a substantially warmer and moister layer capped by the lower inversion, which releases upward latent heat flux, that probably helps in sustaining the mixed layer over a larger depth above the decoupling height, as drier, colder, cloud-driven eddies come into contact with warmer and moister air near the decoupling height. On the other hand, the fact that precipitation falls through a deeper layer might be the main reason why evaporation/sublimation appears more effective in strongly decoupled cases, compared to the weakly decoupled.

To further support our speculations, we theoretically calculated the evaporating rate that is required for a decoupling to occur. As a case study, we used a strongly decoupled profile (DoY 241, 11.31 a.m.) where the sub-cloud layer was disconnected from the surface by a $\sim 1.5^{\circ} \mathrm{C}$ strong inversion. Theoretical estimations revealed that evaporation can cause a cooling of this magnitude within $1-3 \mathrm{~h}$, if evaporating rates are $\sim 0.5-1.5 \mathrm{~mm} \mathrm{day}^{-1}$, assuming that all precipitation evaporates over a $100 \mathrm{~m}$ deep layer. While precipitation rate is difficult to derive from our data set, this simple test shows that our argument that evaporating precipitation may enhance the decoupling does not require excessive precipitation rates.

Other factors may also affect the stratification of the atmosphere, such as horizontal advection in the sub-cloud layer. Furthermore, the fact that, in the strongly decoupled cases, the layer capped by the inversion is often substantially moister than the layer above, with RH reaching saturation, suggests that a secondary cloud layer may be present; cloud radiative cooling at that level could also be related to the abrupt change in stability observed in these cases.

Stably stratified clouds differ substantially from the neutrally stratified clouds; they are geometrically the thinnest clouds observed and are also very low, usually with a cloud base $<\sim 200 \mathrm{~m}$. The observed water properties indicate that these clouds are optically thin, with few droplets; $72 \%$ of stable profiles have LWP $<\sim 50 \mathrm{~g} \mathrm{~m}^{-2}$, suggesting that stable clouds do not contain enough liquid to drive efficient in-cloud mixing, whereas the IWP is close to zero, indicating that they are often liquid only, or at least with very few ice crystals. For the remaining stable cases, that have suffi- cient amount of liquid to produce turbulent motions, the main unanswered question is the distribution of the liquid water in the vertical, e.g., the liquid water content profile. One possibility is that the liquid may not be concentrated near cloud top but rather be distributed more homogenously across the cloud, so that differential cooling within the cloud layer is inhibited, as hypothesized by Sedlar et al. (2012) for the portion of cloud layers that extend into the temperature inversion. Moreover, the CCN concentrations are small for the stable clouds, further supporting that the majority of stable clouds are optically thin; this assumes that the $\mathrm{CCN}$ concentrations observed near the surface are representative of the in-cloud conditions which may not be the case neither when the entire surface-to-cloud layer is stably stratified nor when the clouds are decoupled.

The potential temperature gradient profiles in these stable cases show that surface turbulence usually does not impact the stable clouds and the specific humidity profiles, with increasing moisture with increasing height, indicate that the surface does not serve as a moisture source. The observed Doppler velocities are close to zero suggesting that these clouds are often non-precipitating. The magnitudes of the Doppler spectrum width are very small, which also supports the conclusion that stable clouds are usually not mixed-phase and have little turbulence.

The question remains why these stable clouds contain only liquid. The low $\mathrm{CCN}$ concentration with the optically thin stable clouds is an indication that the air mass for these cases has a low aerosol concentration and it is not unreasonable to expect that this would also mean that IN concentrations are small; Prenni et al. (2007) showed that the concentration of IN is critical to the formation of ice crystals. The fact that IWP is low in these cases may thus be related to the aerosol characteristics. Mauritsen et al. (2011) studied such a case from ASCOS in detail. They hypothesize that, due to the low CCN concentration, the optically thin cloud consists of a small number of relatively large droplets eventually so large that they sediment out of the cloud, hence feeding back on the low $\mathrm{CCN}$ concentration. The presence of large spherical droplets is borne out by the frequent occurrence of so-called fog-bows - a halo-like optical phenomenon that only occurs with relatively large $(20-50 \mu \mathrm{m})$ spherical droplets (Lee, 1998).

The statistical approach of this study does not allow a study of development over time; to further investigate the possible evolution of these clouds we performed a few case studies, based both on cases with very low LWP and slightly higher LWP, $\sim 15 \mathrm{~g} \mathrm{~m}^{-2}$ and $\sim 65 \mathrm{~g} \mathrm{~m}^{-2}$, respectively (not shown). Based on these studies it appears that when the LWP is very low, the cloud slowly becomes more and more tenuous and eventually dissipates; the time for this can be anywhere from half a day up to 2 days; this is consistent with the hypothesis in Mauritsen et al. (2011). In the case with more liquid water, the cloud becomes thicker over time growing upwards and eventually the stably stratified profile gradually 
changes into a neutrally stratified profile and, within hours it gets coupled to the surface as in-cloud turbulence starts. In this case a moisture inversion is present and it is hypothesized the cloud has a homogenous distribution of liquid across its layer as described above, which prevents destabilization of the cloud layer. As it grows up into the moisture inversion, the water supply from this is assumed to cause additional condensation and a redistribution of the liquid in the cloud layer, allowing differential cooling to occur, which eventually leads to the generation of cloud driven turbulence.

Hence, two possible paths for the evolution of stable cloud state appear to be supported: (1) the thinner clouds become more and more tenuous until they dissipate completely. (2) The somewhat thicker clouds increase in optical thickness or achieve changes in the vertical distribution of liquid through more liquid condensate; this allows them to eventually drive turbulent motions which may connect with surface-generated turbulence, considering that the stable clouds are often in very close proximity to the surface ( $\sim$ below $200 \mathrm{~m}$ ) - thus eventually transitioning to a coupled cloud state.

\section{Conclusions}

Arctic low-level clouds and Arctic boundary layer structure have been examined, using observations from the ASCOS expedition, in late summer 2008. In particular, this study focuses on the interactions between low-level clouds and the surface. Profiles of equivalent potential temperature are used to identify neutrally stratified clouds that are thermodynamically "coupled" to, or "decoupled" from, the surface turbulence. Apart from these two cases, where turbulence is generated inside the cloud, a significant number of stably stratified cases are also identified, suggesting the absence of in-cloud mixing for these cases. The vertical structure and properties of these three types: decoupled, coupled and stable clouds, is investigated. This study shows the following.

- Decoupled clouds occur more frequently than coupled. The coupling state is primarily driven by the cloud, through turbulence generated in the cloud by radiative cooling and buoyant processes and is determined by the proximity of the cloud layer to the surface mixed layer. Surface fluxes seem to simply respond to the cloud processes aloft.

- Decoupled clouds exhibit a bimodality in thermodynamic structure, associated with the depth of the sub-cloud mixed layer (SCML); clouds with shallower SCMLs are weakly decoupled from the surface, whereas higher clouds with relatively deeper SCMLs are strongly decoupled. The enhancement of the decoupling for the cases with a deeper SCML is possibly due to evaporation/sublimation of precipitation occurring within the SCML.
- Stable clouds differ substantially from all neutrally stratified states in both thermodynamic and microphysical structure, as well as in geometry and water properties. They are geometrically and optically thin clouds, often single-phase (liquid) with no or negligible precipitation. Some of these cases, based on their proximity to the surface and tenuous nature, represent fog.

Further testing of these conclusions and potential links between the in-cloud dynamics and the cloud and precipitation microphysics, including feedbacks and forcing of the thermodynamic structure, should be further explored using modeling tools (e.g., Solomon et al., 2011, 2014). Also, while this study illustrates the power of surface based remote sensing techniques, more direct in situ profiling of both turbulence and cloud microphysics from the surface and through the clouds, to determine the nature of the coupling, would be highly advantageous.

Acknowledgements. The Arctic Summer Cloud-Ocean Study (ASCOS) was an IPY project under the AICI-IPY umbrella and an endorsed SOLAS project. ASCOS was made possible by funding from the Knut and Alice Wallenberg Foundation, the DAMOCLES Integrated Research Project, EU 6th Framework Program, while the Swedish Polar Research Secretariat (SPRS) provided access to the icebreaker Oden and logistical support. Support from the US National Science Foundation (NSF) and the National Atmospheric and Oceanic Administration (NOAA) for remote sensing instruments is gratefully acknowledged. MT \& JS were funded by the Swedish National Research Council, the Bert Bolin Center for Climate Research and DAMOCLES. IMB was funded by the UK Natural Environment Research Council while MDS and POGP were funded by the NSF. GS was supported by the Office of Naval Research. Finally we are greatly indebted to the Oden's Captain Mattias Peterson and his crew for invaluable assistance with many things during ASCOS.

Edited by: E. Swietlicki

\section{References}

ACIA: Impacts of a warming Arctic: Arctic Climate Impact Assessment, Cambridge University Press, 2005.

Andreas, E. L., Claffey, K. J., and Makshtas, A. P.: Low-level atmospheric jets and inversions over the western Weddell Sea, Bound. Lay. Meteorol., 97, 459-486, doi:10.1023/A:1002793831076, 2000 .

Andreas, E. L., Jordan, R. E., and Makshtas, A. P.: Parameterizing turbulent exchange over sea ice: the ice station weddell results, Bound. Lay. Meteorol., 114, 439-460, doi:10.1007/s10546-0041414-7, 2005.

Bigg, E. K. and Leck, C.: Cloud-active particles over the central Arctic Ocean, J. Geophys. Res., 106, 32155-32166, doi:10.1029/1999JD901152, 2001.

Bintanja, R., van der Linden, E., and Hazeleger, W.: Boundary layer stability and Arctic climate change: A feedback study using EC- 
Earth, Clim. Dynam., 39, 2659-2673, doi:10.1007/s00382-0111272-1, 2012.

Bony, S. and Dufresne, J. L.: Marine boundary layer clouds at the heart of tropical cloud feedback uncertainties in climate models, Geophys. Res. Lett., 32, L20806, doi:10.1029/2005GL023851, 2005.

Comiso, J. C.: A rapidly declining Arctic Perennial Ice Cover, Geophys Res. Lett., 29, 1956, doi:10.1029/2002GL015650, 2002.

Curry, J. A.: Interactions among turbulence, radiation and microphysics in Arctic stratus clouds, J. Atmos. Sci., 43, 90-106, doi:10.1175/1520-0469(1986)043<0090:IATRAM>2.0.CO;2, 1986.

Curry, J. A. and Ebert, E. E.: Annual cycle of radiative fluxes over the Arctic Ocean: Sensitivity to cloud optical properties, J. Climate, 5, 1267-1280, doi:10.1175/15200442(1992)005<1267:ACORFO>2.0.CO;2, 1992.

Curry, J. A., Rossow, W. B., Randall, D., and Schramm, J. L.: Overview of Arctic cloud and radiation characteristics, J. Climate, 9, 1731-1764, doi:10.1175/15200442(1996)009<1731:OOACAR>2.0.CO;2, 1996.

Devasthale, A., Sedlar, J., Koenigk, T., and Fetzer, E. J.: The thermodynamic state of the Arctic atmosphere observed by AIRS: comparisons during the record minimum sea ice extents of 2007 and 2012, Atmos. Chem. Phys., 13, 7441-7450, doi:10.5194/acp-13-7441-2013, 2013.

Frisch, A. S., Fairall, C. W., and Snider, J. B.: Measurement of stratus cloud and drizzle parameters in ASTEX with a $\mathrm{K} \alpha$-band doppler radar and a microwave radiometer, J Atmos. Sci., 52, 2788-2799, doi:10.1175/15200469(1995)052<2788:MOSCAD>2.0.CO;2, 1995.

Graversen, R. G., Mauritsen, T., Tjernström, M., Källen, E., and Svensson, G.: Vertical structure of recent Arctic warming, Nature, 451, 53-57, doi:10.1038/nature06502, 2008.

Harrington, J. Y., Reisin, T., Cotton, W. R., and Kreidenweis, S. M.: Cloud resolving simulations of Arctic stratus - Part II: Transitionseason clouds, J. Atmos. Res., 51, 45-75, doi:10.1016/S01698095(98)00098-2, 1999.

Intrieri, J. M., Shupe, M. D., Uttal, T., and McCarty, B. J.: An annual cycle of Arctic clouds characteristics observed by radar and lidar at SHEBA, J. Geophys. Res., 107, 8030, doi:10.1029/2000JC000423, 2002.

Jakobson, L., Vihma, T., Jakobson, E., Palo, T., Männik, A., and Jaagus, J.: Low-level jet characteristics over the Arctic Ocean in spring and summer, Atmos. Chem. Phys., 13, 110899-11099, doi:10.5194/acp-13-11089-2013, 2013.

Kahl, J. D., Serreze, M. C., and Schnell, R. C.: Low-level tropospheric temperature inversions in the Canadian Arctic, Atmos.Ocean, 30, 511-529, doi:10.1080/07055900.1992.9649453, 1992.

Karlsson, J. and Svensson, G.: The simulation of Arctic clouds and their influence on the winter surface temperature in present-day climate in the CMIP3 multi-model dataset, Clim. Dynam., 36, 623-635, doi:10.1007/s00382-010-0758-6, 2010.

Kapsch, M., Graversen, R. G., and Tjernström, M.: Springtime atmospheric energy transport and the control of Arctic summer sea-ice extent, Nature Clim. Change, 3, 744-748, doi:10.1038/nclimate1884, 2013.
Kay, J. E. and Gettelman, A.: Cloud influence on and response to seasonal Arctic sea ice loss, J. Geophys. Res., 114, D18204, doi:10.1029/2009JD011773, 2009.

Korolev, A.: Limitations of the Wegener-Bergeron-Findeisen mechanism in the evolution of mixed-phase clouds, J. Atmos. Sci., 64, 3372-3375, doi:10.1175/JAS4035.1, 2007.

Lauer, A., Hamilton, K., Wang, Y., Phillips, V. T. J., and Bennartz, R.: The Impact of Global Warming on Marine Boundary Layer Clouds over the Eastern Pacific - A Regional Model Study, J. Climate, 23, 5844-5863, doi:10.1175/2010JCLI3666.1, 2010.

Leck, C., Norman, M., Bigg, E. K., and Hillamo, R.: Chemical composition and sources of the high Arctic aerosol relevant for fog and cloud formation, J. Geophys. Res., 107, 4135, doi:10.1029/2001JD001463, 2002.

Leck, C., Tjernström, M., Matrai, P., Swietlicki, E., and Bigg, K: Can marine micro-organisms influence melting of the Arctic pack ice?, EOS, 85, 25-36, doi:10.1029/2004EO030001, 2004.

Lee, R. L.: Mie theory Airy theory and the natural rainbow, Appl. Opt., 37, 1506-1519, doi:10.1364/AO.37.001506, 1998.

Lindsay, R. W., Zhang, J., Schweiger, A. J., Steele, M. A., and Stern, H.: Arctic sea ice retreat in 2007 follows thinning trend, J. Climate, 22, 165-176, doi:10.1175/2008JCLI2521.1, 2009.

Mahrt, L., Heald, R. C., Lenschow, D. H., Stankov, B. B., and Troen, I.: An observational study of the structure of the nocturnal boundary layer, Bound. Lay. Meteorol., 17, 247-264, doi:10.1007/BF00117983, 1979.

Martin, M., Chang, R. Y.-W., Sierau, B., Sjogren, S., Swietlicki, E., Abbatt, J. P. D., Leck, C., and Lohmann, U.: Cloud condensation nuclei closure study on summer arctic aerosol, Atmos. Chem. Phys., 11, 11335-11350, doi:10.5194/acp-11-11335-2011, 2011.

Maslanik, J. A., Fowler, C., Stroeve, J., Drobot, S., Zwally, J., Yi, D., and Emery, W.: A younger, thinner Arctic ice cover: Increased potential for rapid, extensive sea-ice loss, Geophys. Res. Lett., 34, L24501, doi:10.1029/2007GL032043, 2007.

Mauritsen, T., Sedlar, J., Tjernström, M., Leck, C., Martin, M., Shupe, M., Sjogren, S., Sierau, B., Persson, P. O. G., Brooks, I. M., and Swietlicki, E.: An Arctic CCN-limited cloud-aerosol regime, Atmos. Chem. Phys., 11, 165-173, doi:10.5194/acp-11165-2011, 2011.

Moran, K. P., Martner, B. E., Post, M. J., Kropfli, R. A., Welsh, D. C., and Widener, K. B.: An unattended cloud-profiling radar for use in climate research, B. Am. Meteorol. Soc., 79, 443-455, doi:10.1175/1520-0477(1998)079<0443:AUCPRF>2.0.CO;2, 1998.

Morrison, H., de Boer, G., Feingold, G., Harrington, J., Shupe, M. D., and Sulia, K.: Resilience of persistent Arctic mixed-phase clouds, Nat. Geo., 5, 11-17, doi:10.1038/NGEO1332, 2012.

Nghiem, S. V., Rigor, I. G., Perovich, D. K., Clemente-Colon, P., Weatherly, J. W., and Neumann, G.: Rapid reduction of Arctic perennial sea ice, Geophys. Res. Lett., 34, L19504, doi:10.1029/2007GL031138, 2007.

Nicholls, S.: The dynamics of stratocumulus: Aircraft observations and comparisons with a mixed layer model, Q. J. Roy. Meteorol. Soc., 110, 783-820, doi:10.1002/qj.49711046603, 1984.

Overland, J. E., Spillane, M. C., Percival, D. B., Wang, M., and Mofjeld, H. O.: Seasonal and regional variation of pan-Arctic surface air temperature over the instrumental record, J. Climate, 15, 3263-3282, doi:10.1175/15200442(2004)017<3263:SARVOP>2.0.CO;2, 2004. 
Perovich, D. K., Richter-Menge, J. A., Jones, K. F., and Light, B.: Sunlight, water, and ice: extreme Arctic sea ice melt during the summer of 2007, Geophys. Res. Lett., 35, L11501, doi:10.1029/2008GL034007, 2008.

Persson, P. O. G., Fairall, C. W., Andreas, E. L., Guest, P. S., and Perovich, D. K.: Measurements near the Atmospheric Surface Flux Group tower at SHEBA: Near-surface conditions and surface energy budget, J. Geophys. Res., 107, 8045, doi:10.1029/2000JC000705, 2002.

Pinto, J. O.: Autumnal mixed-phase cloudy boundary layers in the Arctic, J. Atmos. Sci., 55, 2016-2038, doi:10.1175/15200469(1998)055<2016:AMPCBL>2.0.CO;2, 1998.

Pinto, J. O. and Curry, J. A.: Atmospheric convective plumes emanating from leads: 2. Microphysical and radiative processes, J. Geophys. Res., 100, 4633-4642, doi:10.1029/94JC02655, 1995.

Pithan, F. and Mauritsen, T.: Arctic amplification dominated by temperature feedbacks in contemporary climate models, Nature Geosci., 7, 181-184, doi:10.1038/NGEO2071, 2014.

Prenni, A. J., DeMott, P. J., Kreidenweis, S. M., Harrington, J. Y., Avramov, A., Verlinde, J., Tjernström, M., Long, C. N., and Olsson, P. Q.: Can Ice-Nucleating Aerosols Affect Arctic Seasonal Climate?, B. Am. Meteorol. Soc., 88, 541-550, doi:10.1175/BAMS-88-4-541, 2007.

Randall, D., Curry, J., Battisti, D., Flato, G., Grumbine, R., Hakkinen, S., Martinson, D., Preller, R., Walsh, J., and Weatherly, J.: Status of and outlook for large-scale modeling of atmosphere-ice-ocean interaction in the Arctic, B. Am. Meteorol. Soc., 79, 197-219, doi:10.1175/15200477(1998)079<0197:SOAOFL>2.0.CO;2, 1998.

Richter-Menge, J.: The Arctic. [in "State of the Climate in 2009"], B. Am. Meteorol. Soc., 91, 107-124, 2010.

Roberts, G. C. and Nenes, A. A.: continuous-flow streamwise thermal-gradient $\mathrm{CCN}$ chamber for atmospheric measurements, Aerosol Sci. Technol., 39, 206-221, doi:10.1080/027868290913988, 2005.

Sedlar, J. and Shupe, M. D.: Characteristic nature of vertical motions observed in Arctic mixed-phase stratocumulus, Atmos. Chem. Phys., 14, 3461-3478, doi:10.5194/acp-14-3461-2014, 2014

Sedlar, J. and Tjernström, M.: Stratiform Cloud-Inversion Characterization During the Arctic Melt Season, Bound. Lay. Meteorol., 132, 455-474, doi:10.1007/s10546-009-9407-1, 2009.

Sedlar, J., Tjernström, M., Mauritsen, T., Shupe, M. D., Brooks, I. M., Persson, P. O. G., Birch, C. E., Leck, C., Sirevaag, A., and Nicolaus, M.: A transitioning Arctic surface energy budget: the impacts of solar zenith angle, surface albedo and cloud radiative forcing, Clim. Dynam., 37, 1643-1660, doi:10.1007/s00382010-0937-5, 2011.

Sedlar, J., Shupe, M. D., and Tjernström, M.: On the relationship between thermodynamic structure, cloud top, and climate significance in the Arctic, J. Climate, 25, 2374-2393, doi:10.1175/JCLI-D-11-00186.1, 2012.

Serreze, M. C. and Barry, R. G.: Processes and impacts of Arctic amplification: A research synthesis, Global Planet. Change, 77, 85-96, doi:10.1016/j.gloplacha.2011.03.004, 2011.

Serreze, M. C. and Francis, J. A.: The arctic amplification debate, Clim. Change, 76, 241-264, doi:10.1007/s10584-005-9017-y, 2006.
Serreze, M. C., Walsh, J. E., Chapin III, F. S., Osterkamp, T., Dyurgerov, M., Romanovsky, V., Oechel, W. C., Morison, J., Zhang, T., and Barry, R. G.: Observational evidence of recent change in the northern high-latitude environment, Clim. Change, 46, 159-207, doi:10.1023/A:1005504031923, 2000.

Serreze, M. C., Holland, M. M., and Stroeve, J.: Perspectives on the Arctic's shrinking sea-ice cover, Science, 315, 1533-1536, doi:10.1126/science.1139426, 2007.

Shupe, M. D.: Clouds at Arctic Atmospheric Observatories, Part II: Thermodynamic phase characteristics, J. Appl. Meteor. Clim., 50, 645-661, doi:10.1175/2010JAMC2468.1, 2011.

Shupe, M. D. and Intrieri, J. M.: Cloud radiative forcing of the Arctic surface: The influence of cloud properties, surface albedo, and solar zenith angle, J. Climate, 17, 616-628, doi:10.1175/15200442(2004)017<0616:CRFOTA>2.0.CO;2, 2004.

Shupe, M. D., Uttal, T., and Matrosov, S. Y.: Arctic cloud microphysics retrievals from surface-based remote sensors at SHEBA, J. Appl. Meteor. Clim., 44, 1544-1562, doi:10.1175/JAM2297.1, 2005.

Shupe, M. D., Kollias, P., Persson, P. O. G., and McFarquhar, G. M.: Vertical motions in Arctic mixed-phase stratiform clouds, J. Atmos. Sci., 65, 1304-1322, doi:10.1175/2007JAS2479.1, 2008.

Shupe, M. D., Walden, V. P., Eloranta, E., Uttal, T., Campbell, J. R., Starkweather, S. M., and Shiobara, M.: Clouds at Arctic Atmospheric Observatories, Part I: Occurrence and macrophysical properties, J. Appl. Meteor. Clim., 50, 626-644, doi:10.1175/2010JAMC2467.1, 2011.

Shupe, M. D., Persson, P. O. G., Brooks, I. M., Tjernström, M., Sedlar, J., Mauritsen, T., Sjogren, S., and Leck, C.: Cloud and boundary layer interactions over the Arctic sea ice in late summer, Atmos. Chem. Phys., 13, 9379-9399, doi:10.5194/acp-139379-2013, 2013.

Simmonds, I. and Rudeva, I.: The great Arctic cyclone of August 2012, Geophys. Res. Lett., 39, L23709, doi:10.1029/2012GL054259, 2012.

Sirevaag, A., de la Rosa, S., Fer, I., Nicolaus, M., Tjernström, M., and McPhee, M. G.: Mixing, heat fluxes and heat content evolution of the Arctic Ocean mixed layer, Ocean Sci., 7, 335-349, doi:10.5194/os-7-335-2011, 2011.

Solomon, A., Shupe, M. D., Persson, P. O. G., and Morrison, H.: Moisture and dynamical interactions maintaining decoupled Arctic mixed-phase stratocumulus in the presence of a humidity inversion, Atmos. Chem. Phys., 11, 10127-10148, doi:10.5194/acp-11-10127-2011, 2011.

Solomon, A., Shupe, M. D., Persson, P. O. G., Morrison, H., Yamaguchi, T., Caldwell, P. M., and de Boer, G.: The Sensitivity of Springtime Arctic Mixed-Phase Stratocumulus Clouds to Surface-Layer and Cloud-Top Inversion-Layer Moisture Sources, J. Atmos. Sci., 71, 574-595, doi:10.1175/JAS-D-130179.1, 2014.

Stephens, G. L.: Radiation profiles in extended water clouds. II. Parameterization schemes, J. Atmos. Sci., 35, 2123-2132, doi:10.1175/1520-0469(1978)035<2123:RPIEWC>2.0.CO;2, 1978.

Stevens, B., Cotton, W. R., Feingold, G., and Moeng, C.-H: Large-Eddy Simulations of Strongly Precipitating, Shallow Stratocumulus-Topped Boundary Layers, J. Atmos. Sci., 55, 3616-3638, doi:10.1175/15200469(1998)055<3616:LESOSP>2.0.CO;2, 1998. 
Stroeve, J., Holland, M., Meier, W., Scambos, T., and Serreze, M.: Arctic sea ice decline: faster than forecast, Geophys. Res. Lett., 34, L09501, doi:10.1029/2007GL029703, 2007.

Stroeve, J. C., Serreze, M. C., Holland, M. M., Kay, J. E., Malanik, J., and Barrett, A. P.: The Arctic's rapidly shrinking sea ice cover: a research synthesis, Clim. Change, 110, 1005-1027, doi:10.1007/s10584-011-0101-1, 2012.

Tjernström, M.: The summer Arctic boundary layer during the Arctic Ocean Experiment 2001 (AOE-2001), Bound. Lay. Meteorol., 117, 5-36, doi:10.1007/s10546-004-5641-8, 2005.

Tjernström, M., Leck, C., Persson, P. O. G., Jensen, M. L., Oncley, S. P. and Targino, A.: The summertime Arctic atmosphere: Meteorological measurements during the Arctic Ocean Experiment (AOE-2001), B. Am. Meteorol. Soc., 85, 1305-1321, doi:10.1175/BAMS-85-9-1305, 2004a.

Tjernström, M., Leck, C., Persson, P. O. G., Jensen, M. L., Oncley, S. P. and Targino, A.: Experimental equipment: An electronic supplement to "The summertime Arctic atmosphere: Meteorological measurements during the Arctic Ocean Experiment (AOE-2001)", B. Am. Meteorol. Soc., 85, 1322-1322, doi:10.1175/BAMS-85-9-Tjernstrom, 2004b.

Tjernström, M., Zagar, M., Svensson, G., Cassano, J. C., Pfeifer, S., Rinke, A., Wyser, K., Dethloff, K., Jones, C., Semmler, T., and Shaw, M.: Modelling the Arctic boundary layer: An evaluation of six ARCMIP regional-scale models using data from the SHEBA project, Bound. Lay. Meteorol., 117, 337-381, doi:10.1007/s10546-004-7954-z, 2005.

Tjernström, M., Sedlar, J., and Shupe, M. D.: How well do regional climate models reproduce radiation and clouds in the Arctic?, J. Appl. Meteorol. Climatol., 47, 2405-2422, doi:10.1175/2008JAMC1845.1, 2008.

Tjernström, M., Birch, C. E., Brooks, I. M., Shupe, M. D., Persson, P. O. G., Sedlar, J., Mauritsen, T., Leck, C., Paatero, J., Szczodrak, M., and Wheeler, C. R.: Meteorological conditions in the central Arctic summer during the Arctic Summer Cloud Ocean Study (ASCOS), Atmos. Chem. Phys., 12, 6863-6889, doi:10.5194/acp-12-6863-2012, 2012.

Tjernström, M., Leck, C., Birch, C. E., Bottenheim, J. W., Brooks, B. J., Brooks, I. M., Bäcklin, L., Chang, R. Y.-W., de Leeuw, G., Di Liberto, L., de la Rosa, S., Granath, E., Graus, M., Hansel, A., Heintzenberg, J., Held, A., Hind, A., Johnston, P., Knulst, J., Martin, M., Matrai, P. A., Mauritsen, T., Müller, M., Norris, S. J., Orellana, M. V., Orsini, D. A., Paatero, J., Persson, P. O. G., Gao, Q., Rauschenberg, C., Ristovski, Z., Sedlar, J., Shupe, M. D., Sierau, B., Sirevaag, A., Sjogren, S., Stetzer, O., Swietlicki, E., Szczodrak, M., Vaattovaara, P., Wahlberg, N., Westberg, M., and Wheeler, C. R.: The Arctic Summer Cloud Ocean Study (ASCOS): overview and experimental design, Atmos. Chem. Phys., 14, 2823-2869, doi:10.5194/acp-14-2823-2014, 2014.
Twomey, S. A.: The influence of pollution on the shortwave albedo of clouds, J. Atmos. Sci., 34, 1149-1152, doi:10.1175/15200469(1977)034<1149:TIOPOT>2.0.CO;2, 1977.

Uttal, T., Curry, J. A., Mcphee, M. G., Perovich, D. K., Moritz, R. E., Maslanik, J. A., Guest, P. S., Stern, H. L., Moore, J. A., Turenne, R., Heiberg, A., Serreze, M. C., Wylie, D. P., Persson, P. O. G., Paulson, C. A., Halle, C., Morison, J. H., Wheeler, P. A., Makshtas, A., Welch, H., Shupe, M. D., Intrieri, J. M., Stamnes, K., Lindsey, R. W., Pinkel, R., Pegau, W. S., Stanton, T. P., and Grenfeld, T. C.: Surface Heat Budget of the Arctic Ocean, B. Am. Meteorol. Soc., 83, 255-275, doi:10.1175/15200477(2002)083<0255:SHBOTA>2.3.CO;2, 2002.

Wang, X. and Key, J. R.: Arctic Surface, Cloud, and Radiation Properties Based on the AVHRR Polar Pathfinder Data Set. Part I: Spatial and Temporal Characteristics, J. Climate, 18, 2558-2574, doi:10.1175/JCLI3438.1, 2005.

Webb, M. J., Senior, C. A., Sexton, D. M. H., Ingram, W. J., Williams, K. D., Ringer, M. A., McAvaney, B. J., Colman, R., Soden, B. J., Gudgel, R., Knutson, T., Emori, S., Ogura, T., Tsushima, Y., Andronova, N., Li, B., Musat, I., Bony, S., and Taylor, K. E.: On the contribution of local feedback mechanisms to the range of climate sensitivity in two GCM ensembles, Clim. Dynam., 27, 17-38, doi:10.1007/s00382-006-0111-2, 2006.

Westwater, E. R., Han, Y., Irisov, V. G., Leuskiy, V., Kadygrov, E. N., and Viazankin, S. A.: Remote sensing of boundary layer temperature profiles by a scanning 5-mm microwave radiometer and RASS: Comparison experiments, J. Atmos. Ocean. Tech., 16, 805-818, doi:10.1175/15200426(1999)016<0805:RSOBLT>2.0.CO;2, 1999.

Westwater, E. R., Han, Y., Shupe, M. D., and Matrosov, S. Y.: Analysis of integrated cloud liquid and precipitable water vapor retrievals from microwave radiometers during SHEBA, J. Geophys. Res., 106, 32019-32030, doi:10.1029/2000JD000055, 2001.

Zhang, J., Lindsay, R., Schweiger, A., and Steele, M.: The impact of an intense summer cyclone on 2012 Arctic sea ice retreat, Geophys. Res. Lett., 40, 720-726, doi:10.1002/grl.50190, 2013. 